\title{
UMA PROPOSTA DE DESCRIÇÃO ESTRUTURAL PARA RESULTATIVAS
}

\author{
ANDREA KNÖPFLE ${ }^{1}$ \\ (UFPE)
}

\begin{abstract}
RESUMO: O presente artigo apresenta uma proposta de descrição estrutural para construções resultativas, conhecidas na literatura técnica por apresentarem uma semântica de resultado sobre um objeto afetado pelo verbo e preexistente à ação verbal. Sintaticamente, são expressadas na sequência (tipicamente não descontínua) [DP $\mathrm{DP}_{\text {NOM }} \mathrm{V}_{\text {PRINCIPAL }} \mathrm{DP}_{\mathrm{ACC}} \mathrm{AP}$, exemplificadas com o dado do alemão: Er raucht Lungen kaputt - ELE FUMA PULMÕES ESTRAGADOS - 'Ele fuma de forma que pulmões ficam estragados'. Tal construção é tipicamente produtiva em línguas ocidentais germânicas, representadas nesse artigo com dados do inglês, alemão e holandês. Para a análise, levam-se em conta principalmente as características aspectuais da construção, em que a telicidade é construída composicionalmente na sequência [V DP ${ }_{A C C}$ AP]. Propõe-se a existência de um núcleo funcional de natureza aspectual, responsável pelo licenciamento sintático da construção. Como evidência para a existência desse núcleo, tomam-se as construções resultativas que ocorrem na presença de partícula verbal, partícula essa argumentada neste artigo como sendo de natureza aspectual.

Palavras-chave: construção resultativa, partícula verbal, telicidade.
\end{abstract}

ABSTRACT: This works proposes a structural description for resultative constructions, known in the technical literature for having a causative semantics, in which an object is affected by the verb and pre-exists the verbal action. The structure is syntactically expressed by the (typically non discontinuous) sequence [DP $\left.\mathrm{DOM}_{\mathrm{NOM}} \mathrm{V}_{\mathrm{MAN}} \mathrm{DP}_{\mathrm{ACC}} \mathrm{AP}\right]$, exemplified by the example (taken from German): Er raucht Lungen kaputt - HE SMOKES LUNGS RUINED - 'He smokes (in such a way) that the lungs end up damaged'. The construction is typically productive in West Germanic languages, represented in this article with data from German, English and Dutch. The analysis takes into consideration specially the aspectual characteristics of the construction, in which telicity is compositionally built in the sequence $\left[\mathrm{VDP}_{\mathrm{ACC}} \mathrm{AP}\right]$. The existence of a functional head, aspectual in its nature, is proposed. This head provides the syntactic licensing of the construction. The empirical evidence for the aspectual head are the resultative constructions that occur in the presence of verb particles, arguably aspectual in their nature.

Keywords: resultative construction, verb particle, telicity.

${ }^{1}$ deaknoepfle@gmail.com 


\section{INTRODUÇÃO}

\subsection{Sobre resultativas e questões correlatas}

As resultativas são construções gramaticais conhecidas na literatura técnica por apresentarem uma semântica causativa com leitura de resultado. Trata-se de uma sequência tipicamente não descontínua contendo um $\mathrm{V}$ principal, que denota a ação (cujo agente é expresso por um $\mathrm{DP}_{\mathrm{NOM}}$ ), sendo o resultado dessa ação expresso na combinação $\mathrm{DP}_{\mathrm{ACC}}$ e AP (ou PP). Tipicamente, essas construções são produtivas em línguas ocidentais germânicas, tomadas aqui com dados do inglês, alemão e holandês, sendo essas as três línguas objeto de estudo empírico e analítico desse trabalho. Seguem alguns exemplos:

(1) a. Hij schreeuwde zijn keel rauw. (holandês)

a'. He screamed his throat sore. (inglês) Ele gritou sua garganta machucado/inflamado.

'Ele gritou (tanto/de forma tal) que sua garganta ficou machucada/ inflamada.'

b. Zij at zich moddervet. (holandês) ${ }^{2}$

b'. She ate herself very fat. (inglês)

Ela comeu REFL. ${ }^{3}$ muito-gordo

'Ela comeu (tanto/de forma tal) que ficou muito gorda.'

c. He painted the house yellow. (inglês)

Ele pintou a casa amarelo ${ }^{4}$

'Ele pintou a casa, que ficou amarela.'

d. Er hat das Papier naß geniest. (alemão)

Ele teve o papel molhado espirrado

'Ele molhou o papel, espirrando sobre ele./ Ele espirrou, molhando o papel.'

e. He shot him dead. (inglês)

e'. Er schoss ihn tot. (alemão)

Ele atirou ele ${ }_{\mathrm{ACC}}$ morto

'Ele o matou, atirando nele.'

${ }^{2}$ Exemplos (a-b) do holandês de Hoekstra (1988:116).

${ }^{3}$ REFL. abrevia reflexivo.

${ }^{4}$ Nas minhas glossas para o português, os adjetivos estão na aparente forma masculina e singular com a intenção de representar o adjetivo sem marcas de flexão/concordância de gênero e número. Seguindo Mattoso Camara Jr. (1970), o adjetivo das glossas não tem o sufixo flexional ou desinência $-a$ (marcador de feminino) nem $-s$ (marcador de plural); esse adjetivo também não teria o morfema zero marcador de singular nem o morfema zero marcador de masculino. Em alemão, os adjetivos em ambientes predicativos (como é o caso das resultativas) não apresentam marcas de gênero, número ou caso; seria o que Kratzer (2005) chama de adjetivo bare. Sobre o estatuto bare das resultativas, ver Knöpfle (2011). 
O tema é conhecido na literatura técnica, tendo sido discutido por autores como Carrier \& Randall (1992), Levin \& Rappaport (1995), Hoekstra (1988, 1991, 1992), Kratzer (2005) inter alia, trabalhando-se dados do inglês, alemão e holandês. O que resta de mais interessante nesses trabalhos e na sintaxe das construções resultativas de uma maneira geral tem relação com a estrutura argumental do verbo: na grande maioria dos casos, o $\mathrm{DP}_{\mathrm{ACC}}$ que sofre a ação verbal não é subcategorizado pelo verbo, ou seja, o DP ${ }_{\mathrm{ACC}}$ não é argumento semântico de $\mathrm{V}^{5}$ Podemos observar isso nos dados em (1a, b, d). ${ }^{6}$ Trata-se, portanto, de uma questão temática.

Outra questão, decorrente da observação empírica levantada na primeira, tem relação com as condições de licenciamento da construção. Quais seriam os mecanismos sintáticos de seleção verbal que licenciam a sequência $\mathrm{DP}_{\mathrm{ACC}} \mathrm{AP}$ (ou PP)? A hipótese levantada nesse artigo argumenta em favor de a condição de licenciamento das resultativas ser de natureza aspectual.

\subsection{Objetivo e hipótese de trabalho}

Assumindo-se como base empírica as três línguas: inglês, alemão e holandês, o principal objetivo deste trabalho é apresentar uma proposta de descrição estrutural para resultativas. ${ }^{7}$ Propostas de análise e descrição empírica para resultativas já foram apresentadas na literatura técnica. Podemos citar como exemplo os trabalhos de Hoekstra (1988, 1992, 2004) e Kratzer (2005). Resumidamente, o primeiro autor argumenta por uma análise em que a sequência $\left[\mathrm{DP}_{\mathrm{ACC}} \mathrm{AP} / \mathrm{PP}\right]$ forma um constituinte do tipo small clause (SC) complemento do verbo. Nessa análise, a questão sobre a transitividade do verbo não se coloca; uma possível leitura transitiva de $\mathrm{V}$ seria uma espécie de epifenômeno. Já a segunda autora argumenta por uma análise em que o verbo da construção resultativa é sempre intransitivo; a sequência $\left[\mathrm{DP}_{\mathrm{ACC}} \mathrm{AP} / \mathrm{PP}\right]$ também é irmã do verbo, porém não forma uma SC (o AP/PP são tomados como argumento interno do DP). Dentre essas propostas, a que tem maior influência neste artigo é a de Hoekstra, sobretudo porque se corrobora a visão do autor acerca da 'transitividade' do verbo e as restrições de seleção da SC (com ênfase para as questões aspectuais).

Portanto, assim como Hoekstra, argumenta-se aqui que o licenciamento da construção resultativa é de natureza aspectual. Diferentemente de Hoekstra, porém, a hipótese deste artigo é que tal licenciamento ocorra no esqueleto da sentença; em outras palavras, o verbo seleciona uma projeção de natureza aspectual (AspP) que, por sua vez, seleciona a SC. Quanto à AspP, trata-se de uma projeção funcional de natureza aspectual - sendo a base empírica para tal proposta as construções resultativas que coocorrem com verbos de partícula. Se tomarmos (como se argumenta aqui) essas partículas como elementos de natureza aspectual, é preciso prever um lugar no esqueleto sentencial, dentro da análise, para elas.

\footnotetext{
${ }^{5}$ Trata-se de generalização empírica levantada em Knöpfle (2014).

${ }^{6}$ A rigor, no dado (1e') do alemão, o verbo schiessen (atirar) é intransitivo, sendo o DP ${ }_{\mathrm{ACC}}$ não argumento de $\mathrm{V}$.

${ }^{7}$ Para uma maior demonstração empírica, em um único trabalho, de construções resultativas nessas três línguas, remeto o leitor a Knöpfle (2014).
} 
O artigo está dividido da seguinte maneira: na seção 2, aborda-se a estrutura argumental do verbo, com ênfase para a questão temática. A proposta da seção é apoiar a ideia de Hoekstra de que o verbo não tem relação temática com o DP sujeito da SC. Para tanto, apresentam-se testes adicionais aos propostos pelo autor. Em seguida, a seção 3 coloca a assunção de a sequência [DP $\left.{ }_{\mathrm{ACC}} \mathrm{AP}\right]$ formar um constituinte $\mathrm{SC}$. Aqui, busca-se mostrar as restrições de seleção (argumentais e aspectuais) das construções resultativas - basicamente reforçando a argumentação de Hoekstra. Adicionalmente, coloca-se a estrutura interna assumida para a SC como em den Dikken (2006).

O suporte empírico para o licenciamento da construção ser de natureza aspectual leva em conta construções resultativas que coocorrem com verbos de partícula, em que as partículas são colocadas como elementos de natureza aspectual - o assunto da seção 4. Na seção 5, a análise para construções resultativas propõe que o verbo toma como complemento uma projeção de natureza aspectual que, por sua vez, toma a small clause resultativa como complemento. Finalmente, a seção 6 contempla resultativas e verbos inacusativos. ${ }^{8}$

Neste artigo, a base teórico-metodológica para apresentar generalizações empíricas e postular análise se fundamenta em uma metalinguagem formal explícita advinda da Teoria Gerativo-Transformacional, em sua versão de Princípios e Parâmetros pré-minimalista e minimalista (Chomsky 1981, 1986, 1993, 1995; Chomsky e Lasnik 1993; Rizzi 1990, inter alia).

\subsection{Uma breve nota sobre a variação translinguística}

Assume-se neste trabalho, juntamente com Kratzer (2005), Foltran (1999), Rech (2007), Barbosa (2008), Marcelino (2007, 2014), Fonseca de Oliveira \& Marcelino (2014) e Knöpfle (2014, 2017b) inter alia, que o português (e línguas românicas de uma maneira geral) não licencia construções resultativas, pelo menos não com a mesma estrutura das línguas ocidentais germânicas. Uma demonstração empírica convincente e robusta ultrapassa os limites deste artigo (cujo foco é propor uma descrição estrutural para construções resultativas em línguas ocidentais germânicas). Para tal demonstração, remeto o leitor a Kratzer (2005), Foltran (1999), Rech (2007), Barbosa (2008), Marcelino (2007, 2014), Fonseca de Oliveira \& Marcelino (2014) e Knöpfle (2014, 2017b). ${ }^{9}$

\footnotetext{
${ }^{8}$ Por uma escolha metodológico-expositiva, resultativas com verbos inacusativos são abordadas na última seção. Essa escolha se justifica pelo fato de que, conforme apontado por Hoekstra (2004), esse tipo de construção parece oferecer um tipo de exceção para as generalizações empíricas envolvendo resultativas. Adicionalmente, os dados apresentam questões para as análises de resultativas propostas na literatura (em Kratzer e Hoekstra), e também têm consequências para a hipótese de trabalho defendida neste artigo.

${ }^{9}$ A título de exemplificação, seguem os dados agramaticais em PB, moldados (mantendo-se a estrutura) a partir das construções resultativas em (1):

(i) *Ele gritou sua garganta machucada/inflamada.

(ii) *Ela se comeu muito gorda./Ela comeu ela mesma muito gorda.

(iii) *Ele pintou a casa amarela. agramatical na leitura resultativa.

(iv) *Ele espirrou o lenço molhado.

(v) *Ele atirou ele morto.
} 
$\mathrm{Na}$ construção resultativa em línguas ocidentais germânicas, Hoekstra coloca como propriedade (argumental e aspectual) a característica de a SC resultativa conferir telicidade ao evento. Nessa linha de raciocínio, Foltran (1999) aponta ser essa justamente a impossibilidade empírica de ocorrência de resultativas em PB: nessa língua, não são encontradas estruturas em que um predicado secundário resultativo possa transformar um evento atélico (denotado em V) em télico. Tal impossibilidade também é apontada em Rech (2007) como a diferença das construções do PB para as construções encontradas em línguas ocidentais germânicas. ${ }^{10}$

\section{ESTRUTURA ARGUMENTAL}

A questão temática trata do comportamento do $\mathrm{DP}_{\mathrm{ACC}}$ como argumento semântico ou não do verbo. Vejamos os dados:

(2) a. Maria hat ihren Bruder krank geflötet. (alemão)

Maria teve seu irmão doente flauteado

'Maria deixou seu irmão doente, tocando flauta.'

b. The gardener watered the tulips flat. (inglês) O jardineiro regou as tulipas plano 'O jardineiro regou as tulipas, que ficaram achatadas.'

c. Hij kocht de winkel leeg. ${ }^{11,12}$ (holandês) Ele comprou o mercado vazio

'Ele comprou (tanto/de forma tal) e o mercado ficou vazio.'

Em (2a), o verbo "flautear" é intransitivo; o DP "seu irmão" não é argumento de V. Em (2b), "as tulipas" podem ser entendidas como objeto do ato de regar. Em (3c), embora o verbo "comprar" possa ser transitivo, o DP "o mercado" não é objeto do ato de comprar. É importante notar que, em algumas traduções para o português brasileiro, faço uso de intensificadores ou expressões gradativas como

${ }^{10}$ Knöpfle (2017b) traz estruturas do PB muito parecidas com resultativas, chamadas (por exemplo) de pseudoresultativas, i.e. (i) Maria empilhou as almofadas alto e (ii) João varreu o chão bem limpinho. Com base em características sintáticas e morfológicas diferenciadas de resultativas, a autora objetiva demonstrar e sustentar, empiricamente, a argumentação para a distinção entre resultativas e construções similares.

${ }^{11}$ Exemplo do holandês de Hoesktra (1988:115).

${ }^{12} \mathrm{O}$ alemão e o holandês são conhecidos como línguas V2, em que V se move para I, e I se move para C, carregando consigo V, ou seja, o complexo V+I se aloja em C (em orações matrizes). Nesse sentido, a ordem dos constituintes do alemão e do holandês em sentenças em que o verbo matriz é finito pode ser tomada como uma consequência da característica V2 da língua. Adicionalmente ao efeito V2 dessas línguas, elas apresentam a característica de língua V-final. Ou seja, em sentenças subordinadas ou com verbo auxiliar, o verbo matriz ocupa a posição final (permanecendo na sua posição de origem). Assim, nas resultativas com V finito, esse está na posição 2; nas resultativas com verbo auxiliar, o núcleo $\mathrm{V}$ ocupa obrigatoriamente a última posição na sentença. 
"tanto/de forma tal". Trata-se apenas de um recurso para facilitar a compreensão do sentido/contexto pragmático. A interpretação gradativa, embora possível em algumas resultativas, não é condição necessária na ocorrência da estrutura. Para um evento de "hammer the metal flat", ${ }^{13}$ por exemplo, é possível pensar em um contexto em que uma única "martelada" deixa o "metal achatado". Adicionalmente, a interpretação gradativa não é generalizável para todas as resultativas, haja vista exemplos como (1d) e (1e), com os verbos "espirrar" e "atirar", respectivamente. ${ }^{14}$

Existe também a possibilidade de a resultativa ter uma interpretação ambígua em termos de o $\mathrm{DP}_{\mathrm{ACC}}$ ser ou não argumento de V; vejamos:

(3) a. Hans hat seine Hand kaputt gehämmert.

(alemão)

Hans teve sua mão machucado martelado

b. Hans hammered his hand sore.

Leitura 1: 'Hans martelou sua (própria) mão, que ficou machucada por conta disso.' leitura transitiva

Leitura 2: 'Hans martelou (algo), e porque ele fez isso (de forma tal ou durante horas), sua mão ficou machucada.' leitura intransitiva

Se o verbo seleciona ou não o $\mathrm{DP}_{\mathrm{ACC}}$ tem sido assunto controverso. Por exemplo, Carrier \& Randall (1992) e Levin \& Rappaport (1995) argumentam que as resultativas podem ser transitivas ou intransitivas; já Kratzer (2005) defende que o verbo da construção é sempre intransitivo. Hoekstra (1988, 1991, 1992, 2004), por outro lado, argumenta que não se trata de o verbo ser transitivo ou não - o que observamos como leitura do $\mathrm{DP}_{\mathrm{ACC}}$ como semanticamente selecionado pelo verbo é um epifenômeno. Segundo o autor, o verbo seleciona uma SC complemento (assunto da próxima seção), e a possível leitura do $\mathrm{DP}_{\mathrm{ACC}}$ como argmento de $\mathrm{V}$ é o que o autor chama de shadow effect. Em resultativas com leitura transitiva, como "water the tulips flat" ou "hammer the metal flat", a implicação de que "as tulipas" são regadas ou "o metal" é martelado é tomada como sendo "... a consequence of real world knowledge, not theta marking by the verb ..." (ibid, 2004:340). ${ }^{15}$

\footnotetext{
${ }^{13}$ Resultativa prototípica da literatura técnica:
}

(i) He hammered the metal flat. (inglês)

Ele martelou o metal plano

'Ele martelou e o resultado foi o metal plano/achatado.'/ 'Ele achatou o metal, martelando-o'.

${ }^{14}$ Igualmente, nada impede (em um contexto possível) que: em (1a) um único grito, em (1c) uma única borrifada de tinta, em (2a) um único apito de flauta, em (2b) um único arremesso de água ou em (2c) uma única compra deem conta da completude do evento.

${ }^{15}$ De maneira semelhante, Kayne (1985) sugere como sendo pragmática a possibilidade de interpretação do sintagma Acc como argumento do verbo. 
Adicionalmente, o autor coloca que a implicação de que o objeto é lido como argumento do verbo pode ser cancelada em algumas ocasiões, citando como exemplo o dado:

(4) I have painted my fingers black and blue when I painted the walls. ${ }^{16}$ Eu tive pintado meus dedos preto e azul quando eu pintei as paredes 'Quando eu pintei as paredes, meus dedos ficaram roxos/contundidos.'

Como suporte empírico para a argumentação de que a leitura transitiva pode ser cancelada com a devida manipulação do contexto, proponho alguns testes de cancelamento de transitividade. Vejamos o teste em dados do alemão:

(5) a. Wenn er das Holz über dem Metall hämmert, hämmert er das Metall flach. ${ }^{17}$ Quando ele a madeira sobre o metal martela, martela ele o metal plano 'Quando ele martela a madeira, que está sobre o metal, ele achata o metal.'

Contexto: o sujeito, ao martelar uma tábua de madeira, que está sobre uma superfície de metal irregular/curvada, acaba deixando o metal plano. Nesse contexto, podemos também dizer:

b. Er hat das Metall flach gehämmert, ohne das Metall zu hämmern. Ele teve o metal plano martelado, sem o metal $\mathrm{INF}^{18}$ martelar 'Martelando, ele deixou o metal achatado, mas sem martelar o metal.'

(6) a. Als er seine Blumen gegossen hat, goss er leider die Tulpen ein Stockwerk unten vom Nachbar flach.

Quando ele suas flores regado teve, regou ele infelizmente as tulipas um andar abaixo do vizinho plano

'Ao regar suas flores, infelizmente ele achatou as tulipas do vizinho um andar abaixo.'

Contexto: o sujeito mora no segundo andar, e, ao regar suas flores, que ficam na beirada da janela, acabou regando sem querer também as tulipas da beirada da janela do vizinho do andar de baixo, e como resultado dessa 'regação' desastrada, acabou tombando/achatando as tulipas do vizinho. Nesse contexto, podemos também dizer:

b. Er hat die Tulpen flach gegossen, ohne die Tulpen zu giessen. Ele teve as tulipas achatado regado, sem as tulipas INF regar 'Numa ação de regar, ele deixou as tulipas achatadas, sem no entanto regar as tulipas.'

${ }^{16}$ Exemplo de Hoekstra (1988:117). Apesar de o autor não fazer referência a uma resultativa 'ambígua', é com base em dados como (4) minha argumentação de que resultativas podem ser ambíguas quanto à possibilidade de $\mathrm{o} \mathrm{DP}_{\mathrm{ACC}}$ ser interpretado como argumento semântico do verbo ou não.

${ }^{17}$ Notamos aqui o comportamento V-final da língua na sentença subordinada [Wenn er das Holz über dem Metall hämmert], que se move para Spec/CP; notamos também a característica V2: o verbo da matriz [[subordinada $]$ hämmert er ...] se aloja em C, ocupando a posição 2 da oração.

${ }^{18}$ A glossa INF se refere ao marcador de infinitivo em sentença encaixada infinitiva. 
O teste mostra ser possível cancelar a leitura transitiva, mesmo nos exemplos prototípicos da literatura para resultativas 'transitivas'. ${ }^{19}$ No nível de análise relevante, i.e. descrição estrutural, portanto, a resultativa não seria nem transitiva nem ambígua. $\mathrm{O}$ efeito de transitividade ou ambiguidade não se dá nem no nível sintático nem no semântico, mas sim no nível pragmático. De acordo com essa análise, assumida aqui, as resultativas 'ambíguas' ou 'transitivas' assim o são apenas de forma aparente, como efeito da pragmática.

O que se busca concluir desses testes é que, uma vez não havendo a necessidade de atribuição de papel temático para o DP, não há por que se prever na estrutura tal atribuição. Por 'não necessidade de atribuição de papel temático' entende-se que há um contexto em que uma possível leitura do DP como argumento interno de $\mathrm{V}$ possa ser cancelada. ${ }^{20}$ Conforme a expansão do teste originalmente proposto pelo autor sugere, não vejo motivação empírica para se percorrer outro caminho. Vale lembrar que, para a maioria das resultativas, a possível leitura do DP como argumento de $\mathrm{V}$ nem sequer se coloca. ${ }^{21}$

Resta, no entanto, uma questão de seleção lexical para esses verbos: se eles são ambíguos (de uma maneira mais geral) em termos de seleção. No caso do trabalho exposto aqui, ora verbos transitivos selecionam um DP, ora uma $\mathrm{SC}$ resultativa; ora verbos intransitivos não selecionam um $\mathrm{DP}$, ora selecionam uma SC. Não tenho uma solução para essa questão. Lembro, no entanto, que a questão de seleção lexical se coloca na gramática como um todo, para além das resultativas. Verbos intransitivos (inergativos) têm a possibilidade de atribuir acusativo, podendo portanto aparecer em construções com um argumento interno. Verbos (não obrigatoriamente) transitivos apresentam comportamento intransitivo, ficando a questão de onde seria então descarregado o papel temático de argumento interno. ${ }^{22}$ Retomarei a questão na seção 5.

19 Nesse sentido, a resultativa 'ambígua' também teria a interpretação transitiva como consequência do nosso conhecimento de mundo. Ou seja, para (3), a leitura disponível na descrição estrutural é somente a leitura 2: 'Hans martelou (algo), e porque ele fez isso (durante horas), sua mão ficou machucada'. A interpretação de 'algo' como sendo 'a (própria) mão de Hans' é resultado do shadow effect. Ou seja, temos uma 'ambiguidade aparente'.

${ }^{20}$ Essa era justamente a ideia de Hoekstra para não 'afrouxar' o critério theta, o que ficará mais claro na próxima seção quando da exposição das restrições de seleção.

${ }^{21}$ Reforço um esclarecimento sobre a noção de ambiguidade nas resultativas dentro da análise proposta, em que o verbo não tem relação temática com o $\mathrm{DP}_{\mathrm{ACC}}$. Uma possível leitura de argumento interno é que gera a ambiguidade entre transitividade e intransitividade; em essa leitura sendo consequência de um efeito pragmático, a ambiguidade (ou possível leitura transitiva) em questão é um epifenômeno; no nível de análise gramatical relevante, o verbo não tem relação temática com o DP.

${ }^{22}$ Vejamos os exemplos:

(i) Zé dormiu um sono feliz.

(ii) Ana chorou um chorinho bem triste.

(iii) Maria não gosta de comer muito quando faz dieta.

(iv) $\mathrm{Na}$ aula de artes, Joãozinho pintou/desenhou/coloriu o tempo todo. 
Mesmo o $\mathrm{DP}_{\mathrm{ACC}}$ não sendo theta marcado pelo verbo, ele é sempre o objeto afetado pela ação verbal. Hoekstra (1988) se vale da noção de afetação para fazer uma importante generalização sobre resultativas: o DP na SC resultativa é necessariamente interpretado como um 'objeto afetado', em que 'objeto afetado' é entendido como “ (...) an expression referring to an entity which exists independently from the action mentioned by the verb rather than coming into existence through the action." (Hoekstra, 1988:117). A ideia do autor é contrastar a interpretação de affected object com effected object, em que a última é entendida como uma entidade que passa a existir como decorrência da ação verbal. A ambiguidade entre affected object e effected object é observada em 'John paints a house', em que o objeto [a house] pode ser entendido como afetado ou criado. Já tal ambiguidade não se coloca em resultativas (por ex.: John paints the house yellow), em que a única interpretação possível para o objeto é a de afetado (a casa preexistia à ação verbal e passa a ser amarela em decorrência dessa ação).

\section{A SMALL CLAUSE [DP+AP/PP] E RESTRIÇÕES DE SELEÇÃO}

\subsection{Sobre as restrições de seleção da SC resultativa}

A proposta deste artigo segue a generalização de que uma small clause é uma construção que encerra uma relação de predicação, ou uma relação de sujeito-predicado, que não apresenta marcas/flexão de tempo. Assim, a hipótese de trabalho, seguindo Hoekstra $(1988,1992)$, é a de que a sequência [DP AP/PP] forma um constituinte do tipo $\mathrm{SC}$, que representa sintaticamente uma relação de sujeito $\left(\mathrm{DP}_{\mathrm{Acc}}\right)$ e predicado (AP).

O autor assume uma abordagem para SC no sentido de Stowell (1981), em que a definição de sujeito é generalizada para todas as categorias e o rótulo SC é a projeção do núcleo do sintagma resultativo (um AP, por exemplo). Não há um maior desenvolvimento da estrutura interna da SC, sendo relevante apenas que a SC represente a contraparte sintática da relação semântica entre sujeito e predicado.

Para Hoekstra $(1988,1992)$, o verbo seleciona diretamente uma SC, não existindo uma relação temática entre o verbo e o DP sujeito da SC. $\mathrm{O}$ autor apresenta argumentos empíricos e teóricos a favor da hipótese de a SC ser complemento do verbo. Em primeiro lugar, DPs complemento e SCs complemento (resultativas) estão em distribuição complementar, como observamos no paradigma em (7):

(7) a. I drank beer.

a'. I drank him under the table.

a". *I drank beer him under the table/him under the table beer. 
b. He painted the house.

b'. He painted the brush to pieces.

b". *He painted the house the brush to pieces/the brush to pieces the house. ${ }^{23}$

Uma previsão feita pela análise SC complemento para resultativas é de que verbos que obrigatoriamente selecionam um DP complemento não podem participar de uma resultativa. Dentro dessa perspectiva, a agramaticalidade dos dados em (7a") e (7b") se deve à violação do Filtro de Caso (Chomsky, 1981), em que existem dois DPs regidos pelo verbo. ${ }^{24}$ No entanto, Hoekstra (1988) aponta que não é tão fácil testar essa previsão, uma vez que é difícil encontrar bons exemplos de verbos obrigatoriamente transitivos, e, à medida que se encontram exemplos convincentes, a maioria deles pertence à classe aspectual dos verbos estativos. Porém, independentemente do resultado do teste, uma possível não ocorrência de verbos obrigatoriamente transitivos em resultativas não explica o licenciamento da SC resultativa enquanto complemento do verbo (transitivo e intransitivo), segundo o autor. Dessa forma, tratar o licenciamento da SC resultativa em termos da (in) transitividade do verbo não seria suficiente. Lembro que a preocupação do autor está em explicar o licenciamento da SC resultativa enquanto complemento do verbo, sendo ele transitivo ou não. Vale ressaltar, inclusive, que a transitividade do verbo é irrelevante nesse sentido, uma vez que em resultativas cujo $\mathrm{DP}_{\mathrm{ACC}}$ pode ser interpretado como argumento semântico do verbo, tal interpretação é consequência do shadow effect, já que o DP é sujeito da SC.

Em segundo lugar, as restrições de seleção/licenciamento de uma SC resultativa não podem ser as mesmas das encontradas em verbos como consider (considerar) e find (achar), mesmo quando esses selecionam uma SC complemento devido a exigências lexicais. Ou seja, verbos desse tipo selecionam uma SC complemento devido a características lexicais, e essas características são diferentes das encontradas em resultativas. Os dados agramaticais na leitura resultativa em (8) demonstram isso:
a. *I consider John foolish.
(leitura resultativa)
b. *I find the song known. ${ }^{25}$
(leitura resultativa)

Adicionalmente, mesmo $\mathrm{V}$ não selecionando o $\mathrm{DP}_{\mathrm{ACC}}$, existem restrições em relação ao verbo que participa da construção resultativa. Conforme demonstra a agramaticalidade dos dados em (9), em inglês e em alemão, resultativas não são possíveis com verbos de percepção:

${ }^{23}$ Exemplos de Sybesma (1999:13). Sentidos pretendidos: Eu bebo cerveja (de forma tal) que ele fica constrangido (debaixo da mesa) e Ele pintou a casa (de forma tal) e o pincel ficou em pedaços. Ou seja, a agramaticalidade não se dá por razões semânticas/pragmáticas.

${ }^{24}$ Vale notar que essa questão não seria um problema em resultativas intransitivas, em que não haveria dois DPs 'concorrendo’ para checagem de Caso.

${ }^{25}$ Exemplos de Hoekstra (2004:308). Em (8a), John não se torna foolish como consequência da ação verbal; tampouco the song torna-se known por meio do verbo (cf.(8b)). 
(9) a. *Medusa saw the hero stone/into stone. ${ }^{26}$

b. *Der Zauberer hat die Frau schwanger gesehen.

O mágico teve a mulher grávida visto

Sentido pretendido: 'O mágico, com seu olhar, deixou a mulher grávida.'/ 'O mágico viu a mulher, que ficou grávida como consequência de o mágico ter avistado a mulher.'

Outra restrição, de natureza aspectual, é a de que verbos estativos não licenciam resultativas, como se observa nos dados do inglês em (10) e do alemão em (11):

(10) a. *This encyclopedist knows all books superfluous.

b. *The rejected lover hated his girlfriend dead.

c. *I saw myself blind. ${ }^{27}$

(11) a. *Er hat die Frau verrückt/fröhlich geliebt.

Ele teve a mulher maluco/feliz amado

Sentido pretendido: 'Ele amou a mulher de tal forma que ela ficou maluca/feliz.' / 'Ele deixou a mulher maluca/feliz por amá-la.

b. *Er mochte die Frau verrückt/fröhlich

Ele gostou a mulher maluco/feliz

Diante dos dados (9)-(11), a generalização que se segue, segundo Hoekstra, é a de que somente predicações dinâmicas (denotadas pelo verbo matriz) e não inerentemente delimitadas (no conteúdo lexical do verbo) é que podem licenciar uma resultativa. Nesse sentido, o licenciamento da SC resultativa se dá com base nas características aspectuais do verbo. Mais especificamente, a SC complemento torna uma predicação atélica em télica, à medida que denota o estado em que o evento termina. Assim, podemos contextualizar os tipos verbais que ocorrem em resultativas da seguinte maneira: somente predicados eventivos sem uma especificação inerente de um ponto de terminação é que podem se combinar com a SC resultativa. A função da SC é especificar o ponto final da atividade denotada pelo verbo (enquanto predicado eventivo).

${ }^{26}$ Dado em inglês de Hoekstra (1988:118).

27 Exemplos de Hoekstra (1992:156). Os sentidos pretendidos são: (10a) O fato de o enciclopedista conhecer todos os livros os tornam supérfulos; (10b) O amante rejeitado teve ódio e o resultado disso foi sua namorada morta; (10c) Eu enxerguei/vi (tanto/de forma tal) que fiquei cego como resultado disso. 
Interpretando a análise de Hoekstra, a previsão então é de que somente verbos dinâmicos (denotam processo) e não inerentemente delimitados possam participar de uma resultativa. Esses verbos são conhecidos como verbos de atividade (na classificação vendleriana ${ }^{28}$ ). A diferença entre verbos de atividade e accomplishments/ achievements é que os últimos têm um ponto de terminação, ao passo que as atividades não têm. Ou seja, a SC transforma a eventualidade em um accomplishment, à medida que a SC fornece o ponto de terminação que a atividade (predicado matriz) antes não tinha. Seguindo essa análise, é de se esperar então que verbos accomplishment/ achievements não possam participar de uma resultativa, pois já possuem um ponto de terminação definido no conteúdo lexical do verbo matriz. ${ }^{29}$

Resumindo, para Hoekstra (1988, 1992), o verbo seleciona diretamente uma SC, sendo tal seleção licenciada segundo as propriedades aspectuais do verbo. A formalização desse licenciamento é basicamente de cunho semântico, dada por meio da saturação de e-roles (papeis de evento) dentro de uma cadeia temporal..$^{30,31}$

28 Vendler (1967) divide os eventos em quatro classes aspectuais: atividades, estados, accomplishments e achievements. Vejamos a distinção dessas classes, segundo Rothstein (2004): os estados são caracterizados como eventualidades totalmente homogêneas até o seu menor instante, onde cada subparte de um estado é o próprio estado. Já as atividades são eventualidades dinâmicas e homogêneas até intervalos mínimos, onde esses intervalos mínimos têm um determinado tamanho. Ou seja, há eventos mínimos dentro da atividade, mas não podemos dizer que qualquer instante dentro da atividade é a atividade em si. Por exemplo, na atividade dançar valsa, existem intervalos mínimos que ainda são dançar valsa, mas dar apenas um passo não significa dançar valsa, apesar de fazer parte dela. Os achievements são mudanças de estado que ocorrem instantaneamente. Já os accomplishments são eventualidades complexas com certa duração, e apresentam um ponto de culminação. Rothstein (2004) contrapõe estados a atividades, accomplishments e achievements, à medida que estados são caracterizados como eventualidades totalmente homogêneas até o seu menor instante, onde cada subparte de um estado é o próprio estado.

${ }^{29}$ A exemplo de kill - como vemos no dado agramatical de Hoesktra (1992:161) *The psychopath killed the village into a ghost town (sentido pretendido: O psicopata matou (pessoas) e o resultado foi a vila virar uma cidade fantasma). No entanto, temos dados como He killed him dead - nesse caso, poderíamos pensar que uma SC em um verbo accomplishment/achievement atuaria como um modificador, ou seja, a SC não seria uma SC complemento, mas sim uma SC modificador/ adjunto, e a estrutura seria uma 'aparente' resultativa (possivelmente com um PRO na posição de sujeito da SC: [He killed him ${ }_{\mathrm{i}}\left[P R O_{\mathrm{i}}\right.$ dead]]). Dessa maneira, dado semelhante em PB pode ser produzido: Ela matou ele bem mortinho. Knöpfle (2017a) aborda dados desse tipo em PB.

${ }^{30}$ A SC teria um e-role que se liga a um intervalo de tempo $\mathrm{t}_{\mathrm{n}}$ em aberto no verbo matriz (essencialmente télico), saturando esse tempo $t_{n}$ e conferindo telicidade ao evento. O licenciamento da SC resultativa envolveria uma saturação do e-role da SC pelo tense, lexicalmente fornecido pela estrutura temporal do predicado matriz. $\mathrm{O} \mathrm{t}_{\mathrm{n}}$ de $\mathrm{V}$ pode ser theta-marcado por meio de ligação (binding) com um e-role em posição de complemento, no caso uma SC que denota um estado. Ou seja, a saturação do e-role da SC é entendida como uma operação de theta-binding entre o e-role da SC com o $t_{n}$ do predicado matriz. Nas resultativas, a SC (enquanto predicado) tem um papel de evento. O predicado matriz (enquanto verbo de atividade) tem uma posição aberta $\left(\mathrm{t}_{\mathrm{n}}\right)$. O e-role da SC serve de argumento à posição aberta $\mathrm{t}_{\mathrm{n}}$ do predicado matriz. $\mathrm{O}$ predicado matriz também tem um e-role, que é saturado por $T($ ense) por meio de ligação-theta.

${ }^{31}$ Uma alternativa de análise seria repensar a ideia de e-role de Hoekstra: verbos como paint poderiam selecionar argumentos com traço [+télico] (AspP) ou [-télico] (DP), enquanto verbos estativos (que não permitem small clauses resultativas) só poderiam selecionar complementos com traço [-télico] (DP). Agradeço a parecerista anônimo pela sugestão. Como a questão de (ambiguidade de) seleção se mostra um fenômeno mais abrangente da gramática, verificar as consequências empíricas da proposta fugiria dos limites do presente artigo. 
Diferentemente, neste artigo, a proposta é de que o licenciamento ocorra no nível sintático, i.e. no próprio esqueleto da sentença, por meio de uma projeção funcional de natureza aspectual. Em outros termos, V seleciona uma projeção de natureza aspectual (AspP) que, por sua vez, seleciona a SC.A base empírica para essa proposta se pauta nas construções resultativas que coocorrem com verbos de partícula. Sendo as partículas defendidas como elementos de natureza aspectual, é preciso levar em consideração na proposta um "lugar" para elas na descrição estrutural. Essa demonstração empírica é abordada na próxima seção. Antes, porém, é pertinente apresentar a estrutura interna da SC assumida aqui, estrutura essa que também será assumida para a projeção aspectual que licencia a construção resultativa.

\subsection{A estrutura da small clause}

A estrutura interna da SC é tomada neste trabalho como sendo uma instância da projeção R(elator)P(hrase) (seguindo os trabalhos em den Dikken, 2006, 2007a, $2007 \mathrm{~b}$, bem como a teoria de localidade subjacente). Nessa proposta, todas as relações de predicação são mediadas por um núcleo funcional abstrato (o RELATOR), responsável por estabelecer a relação (sintática e semântica) entre o predicado e seu sujeito na estrutura sintática. O esquema pode ser visualizado em (12):

\section{(12) a. $\left[_{\mathrm{RP}}\left[{ }_{\mathrm{XP}} \mathrm{SUBJECT}\right]\left[_{\mathrm{R}}, \mathrm{RELATOR}\left[_{\mathrm{YP}}\right.\right.\right.$ PREDICATE $\left.\left.]\right]\right]$}

A relação de predicação deve ocorrer dentro do sintagma RP, dando conta da localidade da predicação, isto é, a predicação deve acontecer no domínio mínimo do RELATOR e ser mediada por ele. Quanto à natureza do RELATOR, não se trata de uma nova categoria funcional ou de um elemento funcional específico, mas de um placeholder para abrigar qualquer núcleo funcional na estrutura que faça a mediação da predicação entre dois termos. Assim, este núcleo pode ser nulo ou ocupado por uma preposição funcional, um T ou um Infl, ou uma cópula, por exemplo. Enquanto núcleo funcional, R não atribui papel temático, contrariamente aos núcleos lexicais.

Nesses termos, toma-se a SC resultativa como um RP, cujo núcleo funcional $\mathrm{R}$ intermedia a relação sujeito (exercida pelo $\mathrm{DP}_{\mathrm{ACC}}$ ), em $\mathrm{Spec} / \mathrm{RP}$ (a posição XP em (12)), e a relação predicado (exercida pelo AP), em Compl/RP (a posição YP em (12)). Nesse caso, o núcleo R não tem conteúdo fonológico. ${ }^{32}$ A projeção

\footnotetext{
${ }^{32}$ Hipoteticamente, R poderia ser preenchido na resultativa em alguma língua que apresentasse evidência para tanto. Nesse sentido, poderíamos hipotetizar que algum dos afixos presentes em adjetivos de resultativas em outras línguas seja a realização de R. Análise semelhante já foi proposta por outros autores: por exemplo, Asada (2012) analisa em resultativas do japonês o sufixo -ni como núcleo da SC (instanciada como PredP, no sentido de Bowers, 1993) complemento de V, esquematicamente em (ii):

(i) John-ga kabe-o makka-ni nut-ta.

John-NOM wall-ACC very red-NI paint-PAST

'John painted the wall very red.' (Asada, 2012:02)

(ii)

$\mathrm{V}^{\text {PredP }}\left[\right.$ wall ${ }^{\text {PredP' }}$ [red -ni]]
} 
aspectual AspP, complemento de $\mathrm{V}$, que licencia a resultativa, também é tomada como um RP. Nesse caso, R (instanciado como Asp) pode ser preenchido com uma partícula funcional de natureza aspectual, considerando a ocorrência de partículas aspectuais em construções resultativas, como veremos a seguir.

\section{RESULTATIVAS E VERBOS DE PARTÍCULA}

Den Dikken (1995) analisa partículas baseado na argumentação de que se trata de preposições funcionais. Baseado na distribuição sintática, pertencem à categoria P(reposicional). Sintaticamente, partículas são tomadas em den Dikken (1995) como núcleo da SC complemento do verbo, que, por sua vez, toma uma outra SC como complemento ${ }^{33,34}$. A estrutura sintática pode vista esquematicamente em (13)b:

(13) a. They painted the barn up red.

Eles pintaram o celeiro PARTíCULA vermelho

b. $\mathrm{V}\left[{ }^{\mathrm{SC} 1} \ldots\right.$ up $\left[{ }^{\mathrm{SC} 2}[\right.$ the barn $][$ red $\left.\left.]\right]\right]$

'Eles pintaram e o celeiro ficou todo/completamente vermelho.'

A partícula núcleo da SC1 é ergativa, portanto não atribui papel-theta para argumento externo, fazendo com que sua posição de Spec seja um landing site possível para movimento. ${ }^{35}$ A ordem de superfície em (13)a é derivada por meio do alçamento obrigatório do DP (da posição de sujeito da SC2 mais baixa) para a posição vazia em Spec/SC1. O constituinte [the barn] precisa se mover para Checar Caso (em uma configuração ECM). Notamos que não há propriamente um item de vocabulário específico em português equivalente à partícula up no sentido correspondente ao dado; no entanto, ela traz contribuição aspectual reforçando a completude do evento - o que se buscou aqui por meio da tradução com os elementos "todo/completamente".

${ }^{33} \mathrm{O}$ que den Dikken chamou de $\mathrm{SC}_{1}$ e $\mathrm{SC}_{2}$ no trabalho de 1995 foi formalmente analisado em 2006 como um RP que seleciona outro RP. Em 1995, o autor ainda não havia desenvolvido o aparato formal que daria corpo à estrutura de predicação conforme o trabalho de 2006. Não há, no entanto, prejuízo empírico quando da transposição do trabalho de 1995 para a formalização em 2006, não caracterizando portanto um conflito cronológico na exposição aqui.

${ }^{34}$ Den Dikken, no trabalho de 2006, aponta a possibilidade de haver uma projeção AspP acima da SC (assumida como uma estrutura RP). Nesse sentido, para construções com verbo de partícula, a partícula (aspectual) seria o núcleo (com material fonológico) de uma projeção funcional acima da SC $(=\mathrm{RP})$. A proposta de análise desse artigo, portanto, desenvolve ao limite a possibilidade levantada em den Dikken (2006).

${ }^{35}$ Como exemplo da argumentação a favor da ergatividade da partícula, temos o contraste (primeiramente notado em Vanden Wyngaerd (1989)):

(i) They made $(*$ it) out that John is a liar.

(ii) They made *(it) painful that John is a liar.

Em (i), out tem um CP gerado na posição de complemento, bloqueando a inserção de um expletivo. Já em (ii), o adjetivo inergativo requer a inserção do expletivo, uma vez que atribui papel temático de argumento externo ao CP finito que foi extraposto. 
A questão que se coloca, diante do dado em (13a), é se a presença de partículas aspectuais em construções resultativas é possível para outros dados para além desse. A resposta a tal questão é afirmativa. ${ }^{36}$ Vejamos uma amostra de base empírica, feita com testes para dados do alemão. ${ }^{37}$

(14) a. Hans trank das Bierglas leer. (resultativa) Hans bebeu o copo-de-cerveja vazio

'Hans bebeu do copo de cerveja, que ficou vazio.'

b. Hans trank das Bierglas aus. (particula)

Hans bebeu o copo-de-cerveja PRT

'Hans bebeu tudo do copo de cerveja.'/ 'Hans terminou de beber do copo de cerveja.'

c. Hans trank das Bierglas leer aus. (partícula + resultativa)

Hans bebeu o copo-de-cerveja vazio PRT

'Hans bebeu tudo do copo de cerveja, que ficou vazio.'

(15) a. Maria hat den Teller leer gegessen.

(resultativa)

Maria teve o prato vazio comido.

'Maria deixou o prato vazio, comendo o que tinha no prato.'

b. Maria hat den Teller aufgegessen.

(particula)

Maria teve o prato PRT-comido.

'Maria comeu tudo do prato.'

c. Maria hat den Teller leer aufgegessen.

$(\text { partícula }+ \text { resultativa })^{38}$

Maria teve o prato vazio PRT-comido.

'Maria comeu tudo do prato, deixando-o vazio.'

(16) a. Peter brät das Fleisch schwarz.

(resultativa)

Peter assa a carne preto

'Peter assa a carne, que fica preta.'

b. Peter brät das Fleisch an.

$(\text { partícula })^{39}$

Peter assa a carne PRT

'Peter tosta a carne.'

${ }^{36}$ Em inglês, dado semelhante a (13a) pode ser visto em (i) "She grilled the steak up black" (partícula + resultativa). Com verbo intransitivo, temos como exemplo (ii) "Daniel slept his way up to the top" (Daniel dormiu seu caminho partícula para o topo - 'Daniel chegou ao topo dormindo (no sentido sexual')'.

${ }^{37}$ A possibilidade de partículas ocorrerem em construções resultativas é assunto controverso na literatura. Neeleman \& Van De Koot (2002) e Müller (2002) argumentam contra a coocorrência; já Kayne $(1984,1985)$ e den Dikken $(1995,2006)$ argumentam a favor. Minha posição é a de que a coocorrência é possível e toma como base os dados apresentados nessa seção.

${ }^{38}$ Em inglês, o equivalente a esses verbos + partícula seria drink up e eat up.

${ }^{39}$ Repare que braten tem o sentido de assar, enquanto anbraten significa assar até tostar, como se a carne tivesse queimado um pouquinho. 
c. Peter brät das Fleisch schwarz an.

(particula + resultativa)

Peter assa a carne preto PRT

'Peter tosta a carne, que fica preta.'

A presença de partículas em construções resultativas, mesmo sendo possível, apresenta restrições. ${ }^{40}$ No entanto, resta uma quantidade razoável de dados que levam a concluir como possível a ocorrência de construções resultativas envolvendo verbos de partícula (aspectual), conforme já apontado em Kayne (1984) e den Dikken (1995). Assim, tomo essa base empírica como suporte para a proposta de análise de descrição estrutural de resultativas. Em outros termos, os dados embasam a hipótese de que existe um núcleo funcional de natureza aspectual, responsável por licenciar as resultativas.

\section{A PROPOSTA DE ANÁLISE}

\subsection{A sintaxe da construção}

A seção 2 desse artigo apresentou testes empíricos para demonstrar que uma possível interpretação do $\mathrm{DP}_{\mathrm{ACC}}$ como argumento do verbo é pragmática ou atribuída ao nosso conhecimento de mundo. Portanto, a previsão é a de que tal interpretação possa ser cancelada sempre, manipulando-se o contexto. Um ponto que fica em aberto é onde seria então descarregado um possível papel temático do verbo (de argumento interno, entendido com "algo" ${ }^{41}$ ). ${ }^{42}$ Poderíamos supor que se trata de um fenômeno mais abrangente da gramática, como o que acontece em sentenças com verbos tipicamente transitivos usados 'intransitivamente'. Vejamos o paradigma, com exemplos do alemão:

${ }^{40}$ Restrições no sentido de que não são em todas as construções resultativas que podemos inserir uma partícula aspectual. Não tenho uma elaboração mais robusta acerca dessa restrição, mas, por hora, hipotetizo que se dê em virtude da (im)possibilidade de os verbos de ação se combinarem com partículas de uma maneira geral, i.e. formarem construções verbais complexas, para além do tema resultativas. Em outros termos, em não sendo todos os verbos de ação que ocorrem com partículas, não é surpreendente que o mesmo ocorra com construções resultativas e partículas.

${ }^{41}$ Repito aqui o dado relevante mostrado em (3):
a. Hans hat seine Hand kaputt gehämmert.
(alemão)
Hans teve sua mão machucado martelado
b. Hans hammered his hand sore.

leitura 2: 'Hans martelou (algo), e porque ele fez isso (de forma tal ou durante horas), sua mão ficou machucada.' leitura intransitiva

${ }^{42}$ Nas análises de Kratzer (2005) e Hoekstra (1988, 1992, 2004), nos casos em que na resultativa 'transitiva' o verbo está se comportando intransitivamente (para Kratzer) ou o verbo não atribui papeltheta de argumento interno (para Hoekstra), existem as questões de (i) se assumir duas entradas lexicais para o mesmo verbo (para Kratzer) ou (ii) onde é então descarregado o papel theta de argumento interno do verbo (para Hoekstra, e também para a análise defendida aqui). 

(17) a. Sonntags isst der Hans sehr viel.
Aos-domingos come o Hans muito.
'Hans come bastante aos domingos.'
b. Sonntags isst der Hans seinen Teller leer. (resultativa)
Aos-domingos come o Hans seu prato vazio
'Aos domingos, Hans esvazia seu prato, comendo a comida do prato.'

Em ambas as sentenças, não está expresso “o que” o João come propriamente; fica no entanto subentendido - segundo nosso conhecimento de mundo - que João come "algo passível de ser comido". Uma alternativa de análise possível é uma configuração sintática em que $\mathrm{DP}_{\mathrm{ACC}}$ possa receber um segundo papel temático do verbo. ${ }^{43}$ Mas, na falta de motivação empírica para tanto, não vejo o porquê de a descrição estrutural precisar prever alguma marcação temática do verbo para com o $\mathrm{DP}_{\mathrm{ACC}}$. Porém, existindo algum dado em que a interpretação transitiva não possa ser cancelada, a linha de argumentação em termos pragmáticos/shadow effect precisaria ser revista.

Uma segunda questão é se precisamos de fato assumir uma estrutura funcional AspP acima de RP, e quais as consequências dessa hipótese. Nas resultativas (em línguas ocidentais germânicas) não parece existir evidência fonológica para Asp. Porém, quando essas resultativas coocorrem com verbos de partícula aspectual, a partícula pode ser tomada como evidência fonológica para Asp (seguindo den Dikken, 1995). ${ }^{44}$ Nesse sentido, entendo que uma projeção AspP teria a função de licenciar a SC resultativa em termos aspectuais. ${ }^{45}$

Dessa forma, conforme sugerido em den Dikken (2006) e tomando como ponto de partida a teoria de licenciamento aspectual em Hoekstra (1988, 1992, 2004), para a descrição estrutural da resultativa, partirei da hipótese de que existe um núcleo aspectual acima da SC resultativa. De acordo com essa hipótese, em resultativas em que coocorrem verbos de partícula, o núcleo Asp é preenchido pela partícula aspectual; nas demais resultativas, Asp é fonologicamente nulo.

A proposta para a descrição estrutural das resultativas toma o resultado da ação no constituinte [DP AP/PP], que expressa uma relação de predicação entre $\mathrm{DP}$ e AP/PP: o sintagma resultativo (AP/PP) denota o estado alcançado pelo DP por meio da ação verbal. Assume-se que [DP AP/PP] formam uma SC, instanciada como um RP em posição de complemento.

\footnotetext{
${ }^{43}$ A possibilidade de recebimento de múltiplos papéis temáticos para um mesmo DP é assumida nos trabalhos de Hornstein (1999, 2001), Boecks \& Hornstein (2003, 2004, 2006), Hornstein \& Polinski (2010), Boeckx, Hornstein \& Nunes (2010) e Rodrigues (2004a, 2004b, 2010).

${ }^{44}$ Vale lembrar que Dikken (2006) sugere - porém não desenvolve - a ideia de que haveria uma projeção AspP entre a SC resultativa e o verbo matriz.

${ }^{45} \mathrm{O}$ meu uso do termo aspecto, neste trabalho, faz referência ao aspecto interno do evento (inner aspect), no sentido de aspecto lexical (relacionado às classes aspectuais ou Aktionsarten e caracterizado por propriedades lexicais), em que também se encontra a oposição de télico a atélico.
} 
$\mathrm{O}$ verbo matriz, que supostamente não é atribuidor de papel temático nem para a $\mathrm{SC}(=\mathrm{RP})$ nem para o DP sujeito dela, tem como complemento uma projeção AspP, cujo núcleo Asp seleciona uma $\mathrm{SC}(=\mathrm{RP}) .{ }^{46}$ Para o inglês, temos a representação em (18):

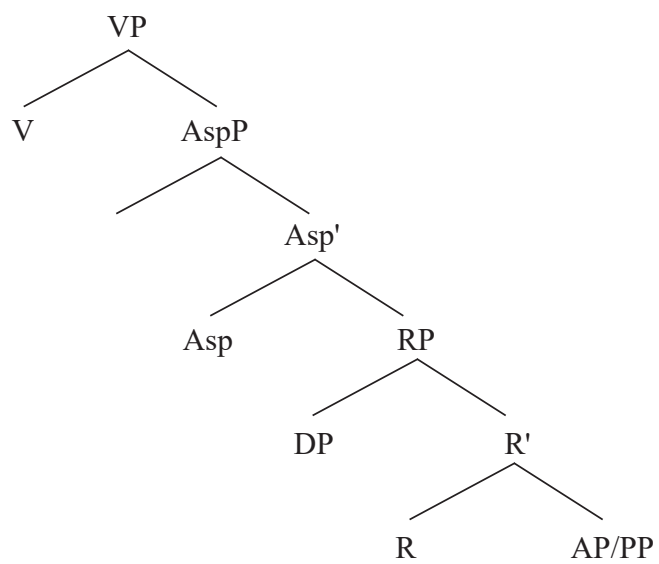

O DP, em Spec/RP (borda da fase) ${ }^{47}$ move-se para Spec/AspP. Evidência para tal movimento é encontrada em construções com verbos de partícula, cuja ordem (amplamente mais aceita) é a V + DP + PRT + AP/PP, como vemos no dado em (19): ${ }^{48}$

(19) a. They painted the barn up red.

b. They painted [the barn $]_{i}$ up $t_{i}$ red.

${ }^{46}$ Vale lembrar que, conforme colocado na seção 3, o núcleo Asp é tomado como uma instanciação de R. Utilizam-se rótulos diferentes, no diagrama, para representar o "RP de cima" instanciado como um AspP. Há, inclusive, a possibilidade de R (que intermedia DP e AP/PP) ser preenchido fonologicamente, conforme apontado na nota 31. Adicionalmente, as propriedades de Asp e R são distintas: R estabelece a relação (sintática e semântica) entre o predicado e seu sujeito na estrutura sintática - essa relação fica evidente quando se toma o DP em Spec/RP como o sujeito e o AP/PP como predicado (cujo núcleo atribui papel temático ao DP). Asp, por outro lado, licencia em termos aspectuais a construção resultativa. A relação sujeito-predicado da SC (=RP) se estabelece independentemente de questões aspectuais, tanto é que essa estrutura é tomada também em outras construções com predicação secundária, para além das resultativas. A necessidade de dois núcleos (Asp e R) na estrutura também se justifica pela composicionalidade semântica (como será exposto na próxima subseção). Nela, Asp, além de licenciar aspectualmente a construção, codifica uma relação de afetação do verbo para com o DP.

${ }^{47}$ Para den Dikken (2006), a projeção RP é uma fase pois encerra uma relação de predicação.

${ }^{48}$ Para o dado em (i), é possível encontrar julgamentos em que a partícula em posição pré $\mathrm{DP}_{\mathrm{ACC}}$ é considerada marginal.

(i) They painted $<1 *$ up $>$ the barn $<u p>$ red $<* u p>$.

Como hipótese de trabalho, vou considerar como posição gramatical a encontrada em (19). A partícula em posição final é agramatical. 
A questão, agora, é como justificar o movimento do DP em construções sem a partícula aspectual (Asp é fonologicamente nulo). Segundo a teoria em Phase Extension (den Dikken, 2006), AspP não é uma fase pois não estabelece uma relação de predicação. Nesse sentido, DP em Spec/RP está visível para operações fora da fase RP (como checagem de Acc, por exemplo). AspP poderia vir a se tornar uma fase quando do movimento (de núcleo) de R para Asp: nesse caso, a fase se estenderia de RP para AspP. AspP sendo uma fase, somente seu Spec (borda da fase) estaria visível para operações fora de AspP, e o DP permanecendo em Spec/RP estaria 'trancado' na fase AspP. O movimento do DP poderia, nessa situação, ser motivado para fins de checagem de Caso. Novamente, qual seria a motivação do movimento de R para Asp? ${ }^{49}$

Nesse ponto, recorro à generalização da interpretação de afetação pelo verbo que esse DP sempre apresenta nas resultativas, conforme exposto na seção 2 . Hipotetizando que a interpretação de afetação do DP se constrói em uma relação com o núcleo Asp, poderíamos ter uma motivação para o movimento do DP para Spec/AspP: o núcleo Asp contribui com o estado final $(=\mathrm{RP})$ de um evento denotado no VP, e esse estado final afeta o DP que está no seu especificador. Em outros termos, proponho que a interpretação de afetação seja construída estruturalmente em Spec/AspP, sendo que a consequência dessa proposta é o movimento obrigatório do DP para Spec/AspP, mesmo em construções em que a partícula não esteja presente (i.e. Asp é fonologicamente nulo).

Na representação de resultativas em alemão e em holandês, precisamos de uma configuração diferente da em (18) se formos considerar essas línguas como V-final. Para a posição da partícula, a primeira possibilidade é seguir o que parece ser o padrão de ordem das línguas (núcleo-complemento) e tomar a partícula à esquerda de RP, como em (20):

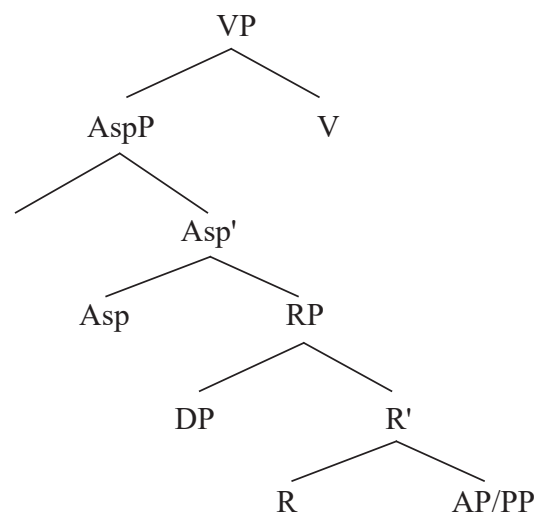

${ }^{49}$ Nas línguas objeto de estudo, R é assumido ser fonologicamente nulo. Nesse sentido, uma possibilidade a ser investigada são resultativas em que o núcleo $\mathrm{R}$ seria fonologicamente preenchido, em alguma outra língua que apresente o fenômeno. $\mathrm{R}$ tendo material fonológico, a investigação empírica seguiria no sentido de verificar o comportamento sintático de R - idealmente, em construções que também apresentassem partículas aspectuais. Deixo essas possibilidades hipotéticas em aberto para investigação futura. 
Nesta configuração, é preciso prever algum movimento de Asp, de forma que a partícula ocupe a posição final. Vejamos alguns dados do alemão em que a posição possível para a partícula está representada em negrito.

(21) a. Sie malten $<*$ an $>$ die Scheune $<*$ an $>$ rot $\quad<\boldsymbol{a n}>$.

Eles pintaram PRT o celeiro PRT vermelho PRT

'Eles pintaram e o celeiro ficou todo/completamente vermelho.'

b. Sie haben $<*$ an $>$ die Scheune $<*$ an $>$ rot angemalt.

Eles tiveram PRT o celeiro PRT vermelho PRT-pintado.

'Eles pintaram e o celeiro ficou todo/completamente vermelho.'

Em (21)a, o verbo matriz exibe o comportamento V2 da língua: V se move para I, e I se move para C, carregando consigo V, e o sujeito se move para Spec/ CP. Em (22)b, na presença de verbo auxiliar, V permanece na posição de origem: a final. Na primeira estrutura, a partícula está em posição final, e, na segunda, está à esquerda do verbo em posição final. Para a configuração em (20) prever a ordem conforme (21), é preciso assumir o movimento de Asp para V. Adicionalmente, para (21)a, é preciso assumir o movimento de $\mathrm{V}$ para I, sem que $\mathrm{V}$ carregue consigo Asp. Ou seja, em (20), assume-se o movimento de Asp para V, e, posteriormente, para (21)a, é preciso ainda assumir a excorporação de V. O movimento de núcleo de Asp para $\mathrm{V}$ formaria um núcleo complexo, ${ }^{50}$ sendo que um posterior movimento de um elemento de dentro desse núcleo complexo (excorporação) é tradicionalmente assumido como ilícito (Marit, 2002; Backer, 1988; Lieber, 1992). Ou seja, uma vez formado um núcleo complexo, ele só poderia se mover como um todo.

Adicionalmente, considerando o movimento de núcleo como adjunção, um posterior movimento de núcleo hospedeiro é problemático por razões estruturais, sobretudo se levarmos em consideração que se trata de movimento de apenas um segmento de categoria (Kayne, 1994) ${ }^{51}$ Nessa teoria, o c-comando é restrito a categorias (e não a segmento de categoria). Um núcleo $\mathrm{X}^{0}$, ao qual outro elemento $\mathrm{Y}^{0}$ foi adjungido, não pode ser movido, pois o núcleo hospedeiro $\mathrm{X}^{0}$ passa a contar como segmento de categoria. Um segmento de categoria sozinho não está disponível para c-comando, portanto um traço de segmento de categoria não pode ser regido por antecedência. ${ }^{52}$ De acordo com essa abordagem, em (20), Asp se adjunge $\mathrm{a} \mathrm{V}$, e $\mathrm{V}$ passa a ser uma categoria de dois segmentos. A excorporação de

${ }^{50} \mathrm{Um}$ exemplo de formação de núcleo complexo é o movimento de $\mathrm{V}$ para I, formando $\mathrm{V}+\mathrm{I}$, seguido do movimento de $\mathrm{V}+\mathrm{I}$ para $\mathrm{C}$ - característico de línguas V2.

${ }^{51}$ Embora Kayne (1994) admita que o movimento do núcleo não hospedeiro seja possível em termos de successive cyclic head movement.

${ }^{52}$ No entanto, o movimento do núcleo não hospedeiro $Y^{0}$ seria possível, uma vez que seu irmão $\mathrm{X}^{0}$, sendo segmento de categoria do núcleo hospedeiro $\mathrm{X}^{0}$, não bloqueia a regência por antecedência do traço do núcleo $\mathrm{Y}^{0}$. Nesse caso, Roberts (1991) assume que a excorporação de $\mathrm{Y}^{0}$ é lícita. Mesmo assim, o movimento de $\mathrm{Y}^{0}$ é controverso. Para a excorporação em termos de successive cyclic head movement, Marit (2002, seção 2.3.2) aponta as consequências empíricas dessa abordagem. A autora conclui a excorporação como uma operação ilícita, mesmo nos casos em que o elemento excorporado não é o hospedeiro, i.e. $\mathrm{Y}^{0}$. Lembro que, no caso das resultativas, a discussão está em mover o núcleo hospedeiro $\mathrm{V}\left(=\mathrm{X}^{0}\right)$, e não o núcleo adjungido $\mathrm{Asp}\left(=\mathrm{Y}^{0}\right)$. 
$\mathrm{V}$ (o núcleo hospedeiro) seria o movimento de apenas um segmento da categoria $\mathrm{V}$, uma vez que Asp adjungido a V ficaria stranded - como mostra o dado (21) a com a partícula (Asp) em posição final e V em posição V2. Segundo Kayne (1994), o problema estrutural dessa configuração, i.e. excorporação de V, é o traço de V não ser regido. ${ }^{53}$

A maior problemática da excorporação, nessa discussão e para além da GB, diz respeito a se fazer uma operação sintática em um segmento de categoria, independentemente de se assumir ou não a teoria de antissimetria conforme Kayne (1994). É nesse sentido que mover um segmento de categoria é incoerente com uma série de assunções elementares dentro do sistema, como, por exemplo, a assunção de que somente categorias estão disponíveis para sofrer determinadas operações. Um exemplo é a operação Agree, dependente de c-comando, que é calculado entre categorias, e não segmento de categorias.

Além da configuração em (20), para a geração de Asp, uma segunda possibilidade é assumir a partícula verbal (Asp) como em posição final, assim como o verbo. Veja-se (22):

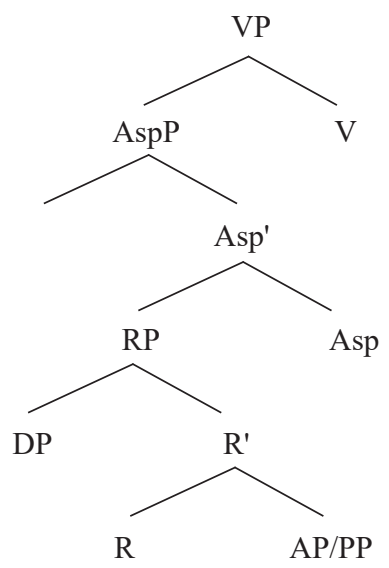

Nessa configuração, não é preciso assumir o movimento de Asp, nem a excorporação de V. No dado em (21)b, a partícula aparece adjacente ao verbo, como um prefixo verbal. No entanto, essa caracterização da partícula como prefixo verbal não necessariamente evidencia o movimento de Asp para V. ${ }^{54}$ Relevante, aqui, é o comportamento sintático da partícula como um constituinte sintático autônomo: na análise, trata-se de um item de vocabulário que preenche Asp - o núcleo responsável por licenciar a resultativa. Empiricamente, podemos ver outras construções resultativas (versões de (21)a) em que a partícula não aparece adjacente ao verbo:

${ }^{53}$ A questão é que o elemento movido precisa c-comandar seu vestígio, sendo, para tanto, preciso haver uma relação de c-comando - relação essa que não se estabelece.

${ }^{54} \mathrm{Não}$ havendo movimento de Asp para $\mathrm{V}$, a sugestão é que se trata de uma convenção ortográfica a partícula enquanto prefixo verbal. 
(23) a. Malen Sie die Scheune bitte rot an!

Pinte o-senhor o celeiro por-favor vermelho PRT

'O senhor por favor deixe o celeiro vermelho, pintando-o!'

a'. *Anmalen Sie die Scheune bitte rot!

PRT-Pinte o-senhor o celeiro por-favor vermelho

b. Es ist leicht, die Scheune rot anzumalen.

Expl. é fácil o celeiro vermelho PRT-ZU-pintar

'É fácil deixar o celeiro vermelho, pintando-o.'

b'. *Es ist leicht, die Scheune rot zuanmalen.

Expl. é fácil o celeiro vermelho ZU-PRT-pintar

Em (23)a, uma construção imperativa, temos o verbo fronteado e a partícula em posição final; se o verbo carregar consigo a partícula, o dado é agramatical (cf. (23)a'). Em (23)b, o marcador de infinitivo [zu] aparece entre partícula e verbo, necessariamente (cf. (23)b'). ${ }^{55}$

Nas resultativas, portanto, assumo a não incorporação de Asp em V, sobretudo porque, assumindo-se essa incorporação, é preciso assumir adicionalmente a posterior excorporação de V quando esse apresenta comportamento V2, ou quando a partícula não está adjacente ao verbo (cf. (23)a). ${ }^{56}$ Conforme já argumentado, a excorporação (principalmente do núcleo hospedeiro) levanta questões importantes e independentes da análise das resultativas. ${ }^{57}$

Assim, a representação em (22) parece ser a menos 'custosa' para as línguas V-final (alemão e holandês). Os dados do alemão e do holandês, diferentemente do inglês, não evidenciam o movimento do DP de Spec/RP para Spec/AspP, uma vez que a posição da partícula é (i) final ou (ii) adjacente ao verbo (esse em posição final). No entanto, com base na hipótese de que a interpretação de afetação do DP é dada estruturalmente em Spec/AspP, assumo para essas línguas o movimento do $\mathrm{DP}_{\mathrm{ACC}}$ de $\mathrm{Spec} / \mathrm{RP}$ para a posição de especificador da projeção funcional aspectual, unificando as análises do inglês, alemão e holandês. Em outros termos, o movimento do DP para Spec/RP é assumido como obrigatório, e sua motivação é a codificação da afetação.

55 Den Dikken (2003:27) aponta a seguinte generalização empírica para línguas ocidentais germânicas e escandinavas: "particles and incorporated nouns can be carried along under V2 iff they can felicitously follow the infinitival marker (surfacing between the infinitival marker and the verb stem)". Ou seja, os dados em (23)b-b'corroboram a generalização: a partícula antecede o marcador de infinitivo [zu] e não pode ser carregada com o verbo quando esse está em posição V2.

${ }^{56}$ Adicionalmente, não me parece haver fenômenos morfofonológicos relevantes que evidenciem a incorporação de Asp em V. No entanto, uma vez se argumentando que essa incorporação de núcleo a núcleo é realizada e tem consequências morfofonológicas, assunções desse tipo precisariam ser devidamente demonstradas. Assim, na ausência de evidências morfofonológicas relevantes, o ônus da prova recai sobre quem propuser que há incorporação com reflexos na morfofonologia da língua. Por hora, a hipótese nula é de que a incorporação não ocorre - hipótese essa a adotada neste artigo.

${ }^{57}$ Den Dikken (2003) (e referências ali citadas) argumenta e demonstra empiricamente que as línguas ocidentais germânicas OV (e seus dialetos) desafiam as análises quando se trata de construções de verbos de partícula. $\mathrm{O}$ autor discute vários casos (inclusive no inglês) em que as partículas mostram autonomia sintática em relação ao verbo, analisando-as como constituintes sintáticos autônomos (i.e. a partícula é núcleo de uma projeção máxima, e não subconstituinte de elementos lexicais), independentemente da maneira como são grafadas (como afixos verbais ou não). 
As representações em (18), para o inglês, e (22), para alemão e holandês, são as hipóteses de descrição estrutural para resultativas, uma vez que parecem dar conta dos dados. No entanto, parte-se da assunção de que alemão e holandês são línguas V-final, apesar de o valor do parâmetro de ordem ser núcleo-complemento.

Rech (2007) se baseia em Folli \& Ramchand (2005) para a descrição estrutural das resultativas, e também para argumentar pela não ocorrência dessas construções em PB. Na análise de Folli \& Ramchand (2005), prevêse a existência de um núcleo (chamado de $\mathrm{R}$, mnemônico para resultado), responsável por integrar a $\mathrm{SC}$ resultativa $\left(\mathrm{DP}_{\mathrm{ACC}}\right.$ e $\left.\mathrm{AP} / \mathrm{PP}\right)$ ao evento. Em outros termos, propõe-se a existência de um R(esultative)P(hrase), que por sua vez seleciona uma SC. Conforme analisa Rech, segundo tal proposta, o núcleo resultativo $\mathrm{R}$ (nulo) tem propriedades de predicador e licencia o aspecto télico ao seu complemento - a SC. As línguas românicas não teriam esse núcleo, não formando portanto resultativas.

Nesse aspecto, a proposta desenvolvida neste artigo tem semelhança com a de Folli \& Ramchand (2005), corroborada por Rech (2007), no sentido de propor um núcleo que licencia aspectualmente a resultativa. A diferença, no entanto, é que no presente artigo o núcleo (chamado de Asp) tem, em algumas ocorrências, seu conteúdo preenchido (quando há a presença de partícula aspectual na construção). Vale ressaltar também que os autores propõem um esqueleto sentencial com outros núcleos verbais que os propostos neste artigo, em que se reflete na sintaxe uma composicionalidade semântica que prevê núcleos de causa, processo e resultado. ${ }^{58}$

A composicionalidade semântica assumida aqui, no entanto, difere daquela, e será colocada na próxima subseção.

\subsection{A composicionalidade semântica}

$\mathrm{Na}$ resultativa, o sintagma adjetival/preposicional denota o estado da entidade denotada pelo DP sujeito da SC. Sintaticamente, DP e sintagma adjetival/preposicional estão em uma relação de sujeito-predicado, por meio da qual o predicado atribui uma propriedade ao sujeito. Foi assumido que o (núcleo do) predicado (AP/PP) da $\mathrm{SC}$ atribui um papel temático ao DP sujeito/ SC. Adicionalmente, conforme a generalização apontada por Hoekstra (1988) e o próprio sentido que se depreende da resultativa, temos o DP como um objeto afetado pelo verbo, mesmo o DP não sendo argumento (interno) de V. Para exemplificar, tomemos um dado:

(24) Er hat das Taschentuch naß geniest.

Ele teve o lenço molhado espirrado

'Ele molhou o lenço, espirrando sobre ele./ Ele espirrou, molhando o lenço.'

${ }^{58}$ Tal estrutura é interessante no sentido de se propor a dar conta de alternâncias causativas. 
O DP [o lenço], sujeito da SC, adquire o estado [molhado], denotado pelo $\mathrm{AP}$, predicado da SC. O verbo é o desencadeador da ação, que resulta no estado [o lenço molhado], denotado na SC. Além disso, podemos entender que o DP [o lenço], que não é argumento do verbo, é afetado pela ação [espirrar]. Em outros termos, o resultado da ação é expresso pela SC [o lenço molhado], sendo que o DP [o lenço] adquire o estado denotado pelo AP [molhado] como consequência da afetação que sofre pelo verbo. O objetivo desse raciocínio é indicar que a afetação (do verbo para com o DP) e a atribuição de propriedade (decorrente da relação de sujeito do $\mathrm{DP}$ com o predicado $\mathrm{AP} / \mathrm{PP}$ ) são duas relações nas quais o DP participa em uma resultativa. A composicionalidade semântica proposta vai procurar contemplar essas duas propriedades do DP na resultativa. A descrição estrutural (abaixo do VP), a partir da qual será esboçada a composicionalidade semântica, foi dada em (18) e é repetida aqui em (25):

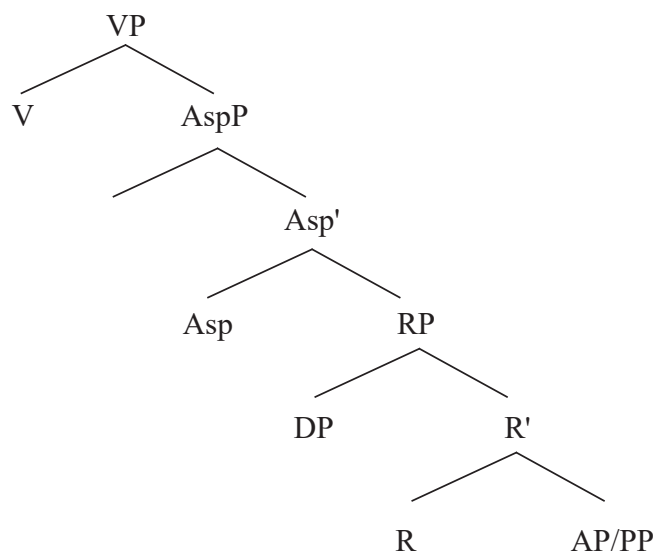

Em Hoekstra (1992), a formalização do licenciamento aspectual da resultativa é dada por meio de uma semântica que envolve saturação de papel de evento (e-role). Resumidamente, a SC resultativa fornece um e-role que é ligado (bind) ao ponto/estágio $\mathrm{t}_{\mathrm{n}}$ (sempre presente e em aberto) no verbo de atividade. Diferentemente, neste artigo, está sendo postulada uma projeção funcional AspP por meio da qual é licenciada a resultativa; essencialmente, o licenciamento nesse caso se dá sintaticamente, à medida que $\mathrm{AspP}$ faz a intermediação entre o verbo (de atividade) e a SC (=RP) resultativa. Nesse ponto, a questão é como se esboçaria a composicionalidade semântica segundo a estrutura representada em (25). Vamos às denotações dos primeiros sintagmas que entram na composicionalidade, tomando como exemplo o dado em (24):

(26) a. $[[\mathrm{DP}]]=[[$ o lenço $]]=\exists \mathrm{x} \mid \mathrm{x}=[$ o lenço $]$

b. $[[\mathrm{AP}]]=[[$ molhado $]]=\lambda \mathrm{x} \exists \mathrm{s}[\operatorname{state}(\mathrm{s}) \& \operatorname{molhado}(\mathrm{x})(\mathrm{s})]$

c. $[[\mathrm{RP}]]=[[(($ o lenço $)$ molhado $)]]=\exists \mathrm{s}[\operatorname{state}(\mathrm{s}) \& \operatorname{molhado}(\mathrm{o}$ lenço $)(\mathrm{s})]$ 
A denotação do RP se dá por meio da combinação, via aplicação funcional, do DP com o AP. Assume-se que R é semanticamente vácuo, portanto a denotação de R' é tomada como a mesma do (seu filho) AP. Vejamos agora a denotação do núcleo Asp:

$$
[[\mathrm{Asp}]]=\lambda \mathrm{P}_{\langle\mathrm{st}\rangle} \lambda \times \lambda \mathrm{e}_{\mathrm{a}}\left[\operatorname{afetação}(\mathrm{x})\left(\mathrm{e}_{\mathrm{a}}\right) \& \mathrm{P}_{(\mathrm{s})} \& \mathrm{tn}_{\mathrm{ea}}=\mathrm{ti}_{\mathrm{s}}\right]
$$

O núcleo Asp introduz uma variável de relação de predicação ' $\mathrm{P}_{(\mathrm{s})}$ ' (que será preenchida pelo RP), em que 's' (subscrito) caracteriza a relação de predicação como um estado. Adicionalmente, na denotação de Asp, temos uma variável de evento ' $\mathrm{e}$ ', em que ' $\mathrm{a}$ ' (subscrito) caracteriza a ação como uma atividade. A variável ' $x$ ' representa a entidade afetada por meio do evento ' $e$ ', e a ideia é que a essa entidade ' $x$ ' seja a mesma que entra na denotação do DP sujeito da SC. $\mathrm{Na}$ denotação de Asp, lê-se ' $\mathrm{tn}$ ea' como uma propriedade aspectual do verbo de atividade, e ' $\mathrm{ti}_{\mathrm{s}}$ ' como uma propriedade aspectual da relação de predicação ' $\mathrm{P}_{(\mathrm{s})}$ ' (o ponto inicial do estado, digamos). Tomando como base a análise de Hoekstra (1992), ' $\mathrm{tn}_{\text {ea }}$ ' representa o ponto/estágio (sempre presente e em aberto) no verbo de atividade, que é igualado ao ponto/estágio ' $t i_{s}$ ', codificando a contribuição aspectual que a relação de predicação (a SC, representada por um RP) traz ao evento, i.e. conferir-lhe telicidade.

Combinando Asp e RP, temos a denotação de Asp', em (28). O próximo passo é a combinação de Asp' a ' $x$ ', formando a projeção AspP, em (29):

(28) $\left[\left[\right.\right.$ Asp' $\left.\left.^{\prime}\right]\right]=\lambda \times \lambda \mathrm{e}_{\mathrm{a}}$ [afetação $(\mathrm{x})\left(\mathrm{e}_{\mathrm{a}}\right) \&[\operatorname{state}(\mathrm{s}) \&$ molhado(o lenço $\left.\left.)(\mathrm{s})\right] \& \mathrm{tn}_{\mathrm{ea}}=\mathrm{ti}_{\mathrm{s}}\right]$

(29) $\left[[\right.$ AspP] $]=\lambda e_{\mathrm{a}}$ [afetação(o lenço) $\left(\mathrm{e}_{\mathrm{a}}\right) \&[\operatorname{state}(\mathrm{s}) \&$ molhado(o lenço)(s) $]$ $\left.\& \mathrm{tn}_{\mathrm{ea}}=\mathrm{ti}_{\mathrm{s}}\right]$

A denotação do verbo está representada em (30). Da combinação de V e AspP, temos a extensão do VP, em (31):

$[[\mathrm{V}]]=[[$ espirrar $]]=\exists \mathrm{e}_{\mathrm{a}}$ [action(e) \& espirrar(e) $]$

(31) $[[\mathrm{VP}]]=[[$ (espirrar $(($ o lenço $)$ molhado $))]]=\exists \mathrm{e}_{\mathrm{a}}\left[\operatorname{action}\left(\mathrm{e}_{\mathrm{a}}\right) \&\right.$ espirrar $\left(\mathrm{e}_{\mathrm{a}}\right) \&$ afetação(o lenço)(e $\left.\mathrm{e}_{\mathrm{a}}\right) \&[\operatorname{state}(\mathrm{s}) \&$ molhado(o lenço) $\left.(\mathrm{s})] \& \mathrm{tn}_{\mathrm{ea}}=\mathrm{ti}_{\mathrm{s}}\right]$

Uma questão que se coloca, segundo a proposta de composicionalidade esboçada, é o que garantiria que a entidade ' $x$ ' na denotação do DP seja a mesma da entidade ' $x$ ' na denotação de Asp. Em outros termos, a questão é como barrar que os referenciais de ' $x$ ' do DP e de ' $x$ ' de Asp não sejam os mesmos, sobregerando dados, a exemplo de (32):

(32) *Er hat das Taschentuch seine Mutter böse geniest.

Ele teve o lenço sua mãe zangado espirrado

Sentido pretendido: 'Ele espirrou, afetando o lenço, de forma que sua mãe ficou zangada como resultado da ação de espirrar que afetou o lenço.' 
A princípio, a composicionalidade semântica tal como apresentada não barra dados do tipo (32). Mesmo que nas denotações de Asp e DP tenha sido usada a variável ' $x$ ', a rigor o núcleo Asp não teria como prever que seu ' $x$ ' seja [o lenço], denotado em RP. Na extensão de Asp há lugar para uma entidade afetada ' $\mathrm{x}$ ' $\mathrm{e}$ uma variável de relação de predicação ' $\mathrm{P}_{(\mathrm{s})}$ ', sendo que não parece possível que a semântica de Asp 'enxergue' o que serve como argumento de predicado dentro da relação de predicação $\mathrm{P}$. Ou seja, não é a denotação de nenhum dos nódulos terminais que garante que ' $\mathrm{x}$ ' de $\lambda \mathrm{x}$ em Asp seja o mesmo ' $\mathrm{x}$ ' dentro de $\mathrm{P}_{(\mathrm{s})}$. Por outro lado, a sintaxe impede que (32) seja possível, uma vez que o DP afetado [o lenço] não recebe papel temático; adicionalmente, temos dois DPs competindo para receber/checar Caso: o DP sujeito da SC e o DP afetado. ${ }^{59}$ Em outros termos, é a sintaxe que garante a não sobregeração de dados, por meio do Critério Theta e do Filtro de Caso (Chomsky, 1981). ${ }^{60}$

\section{SOBRE RESULTATIVAS E VERBOS INACUSATIVOS}

\subsection{Primeiros dados e a polêmica na literatura}

Construções resultativas com verbos inacusativos são assunto polêmico na literatura técnica. Levin \& Rappaport (1995) argumentam que em resultativas com verbos inacusativos o sujeito na estrutura de superfície é o objeto subjacente, ou seja, o objeto da estrutura profunda. ${ }^{61}$ Vejamos dois exemplos com o verbo "freeze" (congelar):

(33) a. The river froze solid.

$\mathrm{O}$ rio congelou sólido

'O rio congelou e ficou sólido.'

b. The prisoners froze to death.

Os prisioneiros congelaram para morte

'O prisioneiros congelaram até a morte.'

\footnotetext{
${ }^{59}$ Mesmo que alguma análise alternativa trate afetação como uma espécie de papel temático (nesse caso o Critério Theta é respeitado), a agramaticalidade seria por violação do Filtro de Caso.

${ }^{60}$ Ao preenchermos ' $\mathrm{x}$ ' de $\lambda \mathrm{x}$ em Asp com [o lenço], e ao preenchermos ' $\mathrm{x}$ ' de $\lambda \mathrm{x}$ no AP também com [o lenço] (formando o RP que vai preencher P), novamente poderíamos questionar: o que garante que não se trata de dois 'lenços' diferentes? Considerando que a sintaxe da construção assume a partir do DP sujeito da SC (i) uma operação de cópia, ou (ii) movimento (deixando um vestígio indexado ao antecedente), ou (iii) remerge, os mecanismos sintáticos subjacentes à construção asseguram que a identidade do argumento ' $\mathrm{x}$ ' dentro de $\mathrm{P}_{(\mathrm{s})}$ seja a mesma do argumento ' $\mathrm{x}$ ' em Asp.

${ }^{61}$ A questão, para as autoras, é manter a Direct Object Restriction (DOR) - generalização segundo a qual o sintagma resultativo é predicado do NP pós-verbal, e não do sujeito nem do complemento oblíquo.
} 
Kratzer (2005), diferentemente, defende que não são encontrados verbos verdadeiramente inacusativos em resultativas. ${ }^{62}$ Um tipo de evidência seria o fato de o verbo "congelar", em alemão, apresentar comportamento misto em relação à inacusatividade. Pensando na argumentação da autora, o verbo "freeze", do inglês, pode se realizar de duas maneiras em alemão: com o auxiliar "sein" (ser) (cf. (34a)) ou o auxiliar "haben" (ter) e presença (obrigatória) do reflexivo (cf. (34)b). ${ }^{63}$

(34) a. Die Gefangenen sind zu Tode/ tot gefroren.

Os prisioneiros foram para morte/ morto congelado

'O prisioneiros congelaram até a morte.'/ 'O prisioneiros congelaram e ficaram mortos por conta disso.'

b. Die Gefangenen haben sich zu Tode/ tot gefroren. Os prisioneiros tiveram REFL. para morte/ morto congelado 'O prisioneiros congelaram até a morte.' / 'O prisioneiros congelaram e ficaram mortos por conta disso.'

Uma outra linha de raciocínio, para distinguir estruturas como em (33) de construções resultativas, seria pensar no adjetivo como modificador de algum estado resultante denotado no conteúdo do verbo, a exemplo das análises feitas para resultativas adverbiais ou pseudoresultativas em Parsons (1990), Geuder (2000), Kratzer (2005), Levinson (2007, 2010), inter alia. Baseando-se na semântica das construções, mais especificamente na função dos modificadores, Parsons (1990) argumenta que, apesar da semelhança estrutural com as resultativas, em dados (a rigor, os VPs) como "chop the onions fine" e "close the door tight", ${ }^{64}$ os modificadores "fine" e "tight" modificam um estado final. Adicionalmente, notamos uma característica aspectual que difere (33) das resultativas analisadas até agora: a sequência $[\mathrm{V}+\mathrm{DP}]$ já possui ponto final, sendo o AP/PP modificador ou especificador do estado final, e não propriamente o que confere telicidade ao evento.

${ }^{62}$ A autora defende uma análise de alçamento para resultativas adjetivais, em que o verbo é sempre intransitivo inergativo.

${ }^{63}$ Tradicionalmente, a seleção do auxiliar sein (ser) é diagnóstico para inacusatividade. A seleção do auxiliar haben (ter) indica que o verbo não é inacusativo.

${ }^{64} \mathrm{Em} \mathrm{PB}$, teríamos o equivalente a "picar as cebolas bem fininhas" e "fechar a porta bem fechada". Para uma abordagem empírico-analítica da necessidade de modificação (intensificador e morfologia adjetival) dessas estruturas em PB, ver Knöpfle (2017a). 


\subsection{Mais dados: resultativas e inacusativos}

Recapitulando a argumentação de Hoekstra (1988, 1992, 2004), em resultativas o $\mathrm{DP}_{\mathrm{ACC}}$ não é argumento do verbo; para a leitura resultativa, a $\mathrm{SC}$ (com seu sujeito e predicado) é que precisam ser o complemento do verbo. Vale notar que, no modelo teórico usado pelo autor (Regência e Ligação), um DP pode receber somente um papel theta; considerando-se que o sujeito da $\mathrm{SC}$ recebe o papel theta do predicado, não há possibilidade de receber mais um papel temático (de argumento interno) de $\mathrm{V}$ - do contrário, haveria violação do Critério Theta (Chomsky, 1981). Assim, Hoekstra mantém a análise de que o verbo não tem relação temática com o sujeito da $\mathrm{SC}{ }^{65}$

Mesmo se mantendo a argumentação de que o verbo (inacusativo, no caso), seleciona uma SC (seguindo Hoekstra, portanto), resta a questão se de fato não existe um papel temático (de argumento interno, não agentivo) de $\mathrm{V}$ a atribuir para o DP sujeito da SC. Até então (conforme demonstrado nos dados colocados neste artigo até agora), o estado resultante é sempre orientado para o objeto acusativo da resultativa, nunca para o sujeito. Existem dados, porém, que parecem contradizer a generalização de que o predicado resultativo é sempre objeto-orientado: trata-se das resultativas formadas com verbos inacusativos (para além das ocorrências de 'aparentes' resultativas ou pseudoresultativas, exemplificadas no início desta seção).

Em (35a), no holandês, o verbo é inacusativo (atestado pela presença do auxiliar "zijn" - "ser") e o sintagma resultativo denota o estado resultante. Em (35b), o mesmo verbo apresenta comportamento inergativo (atestado pela presença do auxiliar "hebben" - "ter"), com a diferença de que nesse dado há a presença do $\mathrm{DP}_{\mathrm{ACC}}$, mostrado na obrigatoriedade do reflexivo.

(35) a. dat het vliegtuig te pletter is gevlogen

que o avião em pedaços é voado

'que o avião voou e ficou em pedaços.'

b. dat het vliegtuig zich te pletter heeft gevlogen

que o avião REFL. em pedaços teve voado

'que o avião voou e ficou em pedaços.'

\footnotetext{
${ }^{65}$ Hoekstra (2004) faz uma demonstração empírica de construções com verbos inacusativos (para além de resultativas), em que o sujeito de superfície não tem relação temática com o verbo. Nesses casos, o autor argumenta que o verbo inacusativo seleciona uma SC. Quando o sujeito da SC pode ser interpretado como argumento semântico do verbo, o autor também atribui essa interpretação ao shadow effect. Assim, Hoekstra não persegue a ideia de uma possível dupla atribuição de papel-theta ao sujeito da $\mathrm{SC}$ em resultativas por acreditar que as evidências são muito poucas para um afrouxamento do Critério Theta. O autor admite, no entanto, ser concebível que pesquisas adicionais tragam evidências mais robustas para se chegar a uma conclusão desse tipo. Relevante é que mesmo a concepção de uma possível dupla atribuição de papel temático não invalida uma análise SC complemento para resultativas.
} 
Vejamos mais alguns exemplos:

(36) a. The vase fell to pieces. (inglês)

$\mathrm{O}$ vaso caiu em pedaços.

'O vaso caiu e ficou em pedaços.'

b. Das Flugzeug ist in Stücke geflogen.(alemão)

O avião é em pedaços voado

'O avião voou e ficou em pedaços.'

c. Die Teller sind kaputt gefallen. (alemão)

Os pratos são estragado caído

'Os pratos caíram e ficaram quebrados por conta da queda.'

Notamos, nos dados do alemão, a presença do auxiliar "sein" (ser), mostrando o comportamento inacusativo dos verbos. Para completar o paradigma, coloco abaixo mais alguns dados de resultativas inacusativas com o verbo "chover", em holandês e em alemão:

(37) a. dat mijn jas nat is geregnet. ${ }^{66}$ que meu casaco molhado é chovido

'que meu casado ficou molhado por ação da chuva.'

b. Meine Jacke ist na $\beta$ geregnet.

Minha jaqueta é molhado chovido

'Minha jaqueta ficou molhada por ação da chuva.'

O verbo "chover" mostra de fato seu comportamento inacusativo, uma vez que não é capaz de atribuir papel temático de agente ao sujeito da sentença (seguindo a generalização de Burzio (1986)). ${ }^{67}$

\subsection{Estendendo a análise para resultativas inacusativas}

Tradicionalmente, espera-se que o verbo inacusativo tenha um argumento interno - pelo menos para os dados em (35) e (36). Nas resultativas 'transitivas' e 'ambíguas', a leitura de argumento interno do verbo é passível de ser cancelada. Já nas resultativas inacusativas como em (35) e (36), mesmo em um contexto pragmático favorecedor, ainda assim não é possível eliminar a leitura do DP como argumento interno de V, conforme vemos em (38).

(38) Contexto: em uma mesa, havia pratos. Acima dos pratos, fixado no teto, havia um lustre. O lustre (por conta de estar mal fixado) se solta e cai em cima dos pratos, resultando em os pratos ficarem quebrados.

${ }^{66}$ Exemplos do holandês de Hoekstra (2004:305).

${ }^{67}$ Curiosamente, o verbo "chover", em alemão, quando usado no sentido de "Choveu", seleciona auxiliar haben (ter), obrigatoriamente, mostrando comportamento inergativo

(i) Es hat geregnet./*Es ist geregnet.

Expl. teve chovido Expl. foi chovido 
a. *Die Teller sind kaputt gefallen.

Os pratos são estragado caído

Sentido pretendido: 'Os pratos ficaram quebrados por conta da queda (do lustre, no contexto sugerido).'

Assim, é preciso levar em conta que nessas resultativas o DP argumento interno do verbo (que é alçado para a posição de sujeito) também é sujeito da SC, ou seja, receberia dois papéis temáticos: um do sintagma resultativo (AP) e um do verbo. ${ }^{68}$ Adicionalmente, precisa-se levar em conta construções em que o verbo inacusativo (a exemplo de (37)) não tem papel temático a atribuir. Nessas últimas, a descrição estrutural abaixo do VP é a mesma das resultativas da seção anterior. A diferença estaria acima do VP, em que, para as inacusativas, não está prevista estrutura para atribuição/checagem de Caso acusativo.

Assumo para as resultativas inacusativas as mesmas condições de licenciamento (aspectual) das demais resultativas; a análise prevê, portanto, uma projeção AspP irmã de V. A evidência, embora rara, está em verbos de partícula inacusativos em resultativas, a exemplo de (39b) - dado do alemão com seleção do auxiliar "sein" (atestando a inacusatividade) e verbo de partícula:

(39) a. Die Teller sind umgefallen.

Os pratos são PRT-caído

'Os pratos tombaram.'

b. Die Teller sind in Stücke umgefallen.

Os pratos são em pedaços PRT-caído

'Os pratos tombaram e ficaram em pedaços.'

Assim, para as línguas V-final, a estrutura (abaixo do VP) proposta pode ser vista em (40a), e, para o inglês, em (40b):

${ }^{68}$ Teorias mais recentes desenvolvidas a partir do Programa Minimalista (Chomsky, 1995) assumem a possibilidade de múltipla atribuição de papéis temáticos a um mesmo DP/NP, sendo Hornstein (1999) e Hornstein (2001) os trabalhos precursores dessa abordagem. A Teoria de Controle por Movimento (Hornstein, 1999, 2001; Boecks \& Hornstein, 2003, 2004, 2006; Hornstein \& Polinski, 2010; Boeckx, Hornstein \& Nunes, 2010; Rodrigues, 2004a, 2004b, 2010) toma controle (a relação anafórica entre o PRO da Teoria de Ligação e seu antecedente) como uma instância de movimento. Em uma cadeia de movimento, conforme assumida pelos autores, um mesmo DP (NP) tem a possibilidade de receber mais de um papel temático ao longo da derivação. 
(40a)

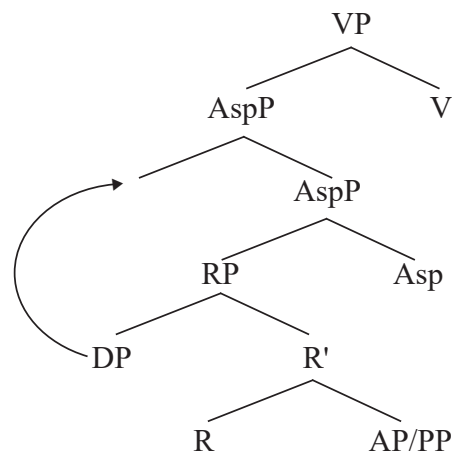

(40b)

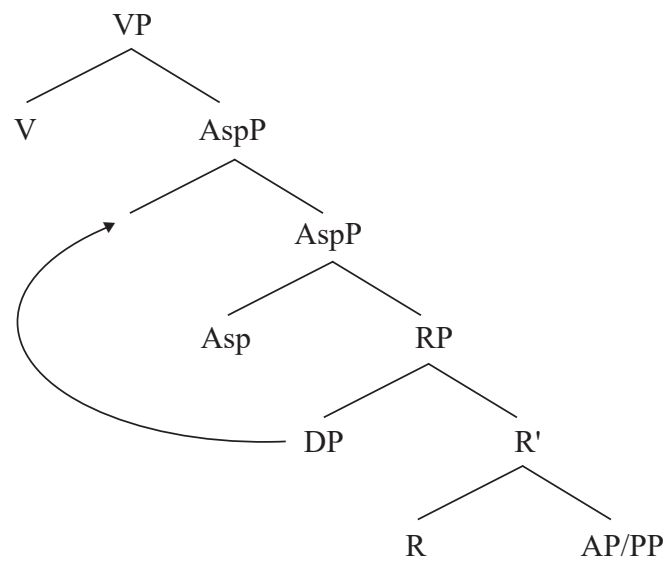

A estrutura para resultativas inacusativas (com $\mathrm{V}$ atribuidor de papel-theta) em (40) difere das estruturas em (18) e (22), proposta para resultativas da seção anterior, no nível da configuração de AspP. Em (18) e (22), a projeção máxima AspP domina imediatamente a projeção intermediária Asp'. Diferentemente, em (40), AspP é uma categoria única com dois segmentos - seguindo as definições padrão de categoria, segmento e dominância, provindas dos trabalhos de May (1985) e Chomsky (1986). ${ }^{69,70}$ É importante frisar que existe apenas uma categoria AspP, tanto em (18) e (22) quanto em (40); a diferença é que a posição antes concebida como Spec de AspP (em (18) e (22)) é adjunto em (40). Em ambas as estruturas, o Spec de AspP ou o adjunto a AspP c-comandam assimetricamente o núcleo Asp e o complemento

${ }^{69}$ Para uma pesada crítica a essa abordagem padrão de dominância e adjunção, ver Pullum (1989). Para uma resposta à crítica, ver Chomsky (1990) e Guimarães (2010). Para uma formalização matemática precisa dessa concepção de c-comando, dominância e adjunção, ver Frank \& VijayShanker (2001) e trabalhos subsequentes.

${ }^{70}$ Apesar de eu não estar assumindo inteiramente Kayne (1994), em que não há projeções intermediárias e todos os especificadores são na realidade adjuntos, esse tipo de configuração estrutural se parece com as de Kayne (1994). A diferença significativa é a de que eu não assumo que tal configuração deva existir em todos os lugares em cada gramática, haja vista a configuração proposta para as resultativas (em que V não atribui papel-theta ao DP sujeito da SC). 
de Asp. Em (40), assume-se o movimento do DP para a posição de adjunto a AspP, posição em que o DP c-comanda Asp e RP. Crucialmente, para os propósitos deste trabalho, o DP adjunto a AspP c-comanda V: a menor categoria que domina o DP/ adjunto é o VP, e não AspP, uma vez que somente um dos dois segmento de AspP domina o DP. Nessa configuração, DP e V se c-comandam mutuamente, em que o c-comando de $\mathrm{V}$ para o DP é trivial e o c-comando do DP para V é o resultado do que se conhece como "super c-comando". ${ }^{71}$ A vantagem da configuração em (40) é que o DP se torna (o segundo) irmão de V, podendo receber o papel temático de argumento interno do verbo inacusativo. Nas resultativas inacusativas em que $\mathrm{V}$ atribui papeltheta ao DP, o movimento do DP (da posição de sujeito de RP para adjunto a AspP) é motivado, pode-se dizer, para fins de recebimento/atribuição de papel temático. $\mathrm{O}$ verbo inacusativo, tendo um papel temático a ser descarregado, precisa de um DP na configuração apropriada que possa receber o papel de argumento interno de $V_{\text {inacusativo }}$. Adicionalmente, esse movimento é necessário para codificar estruturalmente a interpretação de afetação do DP junto ao núcleo Asp.

Uma justificativa para a proposta de duas configurações distintas para resultativas (não inacusativas e inacusativas) é a necessidade de uma configuração (a de adjunção, no caso) em que seja possível a atribuição de papel-theta interno dos inacusativos em verbos que têm esse papel temático a atribuir. $\mathrm{O}$ que barraria uma configuração de adjunção para resultativas não inacusativas seria a sobregeração de dados. A adjunção a AspP, a princípio, abriria a possibilidade de atribuição de papel-theta interno, uma vez que o verbo transitivo está em uma configuração em que é possível a atribuição desse papel temático. No entanto, havendo tal adjunção, o sistema seria capaz de prever como gramaticais dados de resultativas com verbos ditos obrigatoriamente transitivos, i.e. *The bombing destroyed the residents homeless (sentido pretendido: 'A bomba destruiu de forma que os habitantes ficaram sem seus lares'). Formalmente, resta a questão teórica acerca dessa proibição. Especulativamente, a condição de adjunção a AspP somente para certos inacusativos teria relação com a impossibilidade de 'dethematização'/'absorção' de theta interno em certos inacusativos de uma maneira geral e para além das resultativas. Já sobre a possibilidade de adjunção a AspP nos ambientes com verbos intransitivos ou inacusativos sem papel-theta interno, essa adjunção não parece contribuir (uma vez que $\mathrm{V}$ não tem papel-theta interno a descarregar), mas também não parece atrapalhar (a posição de segundo irmão do verbo não é temática, mas o DP já recebeu papel-theta (do núcleo) do predicado).

Sobre a composicionalidade semântica para inacusativas, essa se difere à medida que $\mathrm{V}$ atribui papel-theta interno. Nessa situação, precisamos prever na denotação de $\mathrm{V}$ a presença de um argumento interno, que precisa ser a mesma entidade ' $\mathrm{x}$ ' na denotação de Asp e na denotação do DP. Em relação à sobregeração de dados para essas inacusativas, questão semelhante às demais resultativas é levantada, sendo que para as inacusativas (em que $\mathrm{V}$ atribui papel-theta interno) não podemos impedir, com base no Critério Theta, que dados a exemplo de (41) sejam gerados.

${ }^{71} \mathrm{O}$ "super c-comando" é, na realidade, um epifenômeno, pois não se trata de mais uma espécie de relação de comando, mas sim de uma consequência do c-comando comum obtido em estruturas de adjunção, segundo as teorias e trabalhos desenvolvidos e defendidos em Kayne (1994), Moro (2000), Barrie (2006) e Guimarães (2010). 
(41) *Die Lampe ist den Teller kaputt gefallen.

O lustre é o prato quebrado caído

Sentido pretendido: 'O lustre caiu e quebrou o prato/ O lustre caiu, sendo que a queda do lustre afetou o prato, que por sua vez ficou quebrado.'

A geração de dados como (41) é novamente barrada pela sintaxe, uma vez que o DP afetado [o prato] não tem como receber/checar Caso Acc.

\section{CONSIDERAÇÕES}

Este artigo, com base em levantamento e testes empíricos, apresentou uma proposta de descrição estrutural para construções resultativas em línguas ocidentais germânicas, tomadas com exemplos do inglês, alemão e holandês. A proposta levou em conta a natureza aspectual da construção, em que a telicidade é construída composicionalmente na sequência tipicamente não descontínua $\left[\mathrm{V}+\mathrm{DP}_{\mathrm{ACC}}+\mathrm{AP}\right]$. A proposta levou em conta, empiricamente, construções resultativas com a presença de uma partícula aspectual, tomada como evidência para se postular um núcleo funcional AsP, reponsável pelo licenciamento da construção.

Por razões de escopo e espaço, o PB e línguas românicas em geral não foram abordados para além da assunção de que não apresentam construções resultativas (pelo menos não com a mesma configuração sintática das línguas foco do artigo). Talvez a questão mais intrigante, nesse ponto, seja o porquê dessa variação translinguística. Se a análise proposta nesse trabalho estiver no caminho certo, poderíamos hipotetizar, ainda que especulativamente, que uma razão para a não ocorrência de resultativas em PB tenha relação com a ausência de partículas aspectuais nessa língua. ${ }^{72}$

${ }^{72}$ Snyder $(1995,2001)$ propõe explicar a variação translinguística por meio do Parâmetro de Composição, segundo o qual a pouca produtividade de construções resultativas em uma língua é evidência de marcação negativa para o parâmetro. Nesse sentido, o autor compara o inglês, como exemplo de língua marcada positivamente, e o francês, como língua de marcação negativa. Kratzer (2005) cita o autor como suporte para sua análise sintático-morfológica de licenciamento de resultativas. Marcelino (2007, 2014) e Fonseca de Oliveira \& Marcelino (2014) usam o parâmetro para explicar o porquê o $\mathrm{PB}$, marcado negativamente para o parâmetro de composição, não licencia compostos nominais, resultativas, verbos de partícula, construção com objeto duplo e isolamento de preposição, ao contrário do inglês (marcado positivamente para o parâmetro). Seguem exemplos de Marcelino (2007, p.36):

(i) a. $\mathrm{N}+\mathrm{N}$ compounding: banana box, book worm.

b. Resultative: John wiped the table clean.

c. Verb-Particle: Mary picked up the book/picked the book up.

d. Double Object Dative: Alice sent Sue the letter.

e. Preposition Stranding: I know who Alice sent the letter to.

A não ocorrência em PB das estruturas em (i) é evidência, em Marcelino (2007), de que o PB estaria marcado negativamente para o parâmetro. 


\section{REFERÊNCIAS}

ASADA, Y. Against the complex predicate analysis of secondary predication. Proceedings of ConSOLE XVII, pp. 53-76, 2012.

BAKER, M. Incorporation: a theory of grammatical function changing. Chicago: University of Chicago Press, 1988.

BARBOSA, J. W. C. A estrutura sintática das chamadas "construções resultativas em PB". Dissertação de Mestrado - Faculdade de Filosofia, Letras e Ciências Humanas, Universidade de São Paulo, São Paulo, 2008.

BARRIE, M. J. M. Dynamic antisymmetry and the syntax of noun incorporation. Tese (Doutorado). Universidade de Toronto: Toronto, 2006.

BOECKX, C.; HORNSTEIN, N. Reply to "Control is not movement.". Linguistic Inquiry 34: 269-280. Cambridge, MA: MIT Press, 2003.

BOECKX, C.; HORNSTEIN, N. Movement under control. Linguistic Inquiry 35: 431-452. Cambridge, MA: MIT Press, 2004.

BOECKX, C.; HORNSTEIN, N. The virtues of control as movement. Syntax 9: 118-130, 2006.

BOECKX, C., HORNSTEIN, N.; NUNES, J. Control as Movement. Cambridge University Press: Cambridge, 2010.

BURZIO, L. Italian Syntax: a government and binding approach. Dordrecht: D. Reisel Publishing Company, 1986.

CAMARA JR., J.M. Estrutura da língua portuguesa. Petrópolis: Vozes. 1970.

CARRIER, J.; J. H. RANDALL. The Argument Structure and Syntactic Structure of Resultatives. Linguistic Inquiry 23(2), pp. 173-234, 1992.

CHOMSKY, N. Lectures on government and binding. Dordrecht: Foris, 1981.

CHOMSKY, N. Barriers. Cambridge, Mass.: The MIT Press, 1986.

CHOMSKY, N. On formalization and formal linguistics. Natural language \& Linguistic theory, v. 8 , no 1 , pp. 143-147, 1990.

CHOMSKY, N. Some notes on economy of derivation and representation. In: Principles and parameters in comparative grammar. Robert Freidin (ed.). pp. 417-454. Cambridge, Mass.: MIT Press, 1991.

CHOMSKY, N. A minimalist program for linguistic theory. In HALE, K.; KEYSER, S.J. (eds.). The view from Building 20. Cambridge, Mass.: The MIT Press, 1993.

CHOMSKY, N. The Minimalist Program. Cambridge, Mass.: The MIT Press, 1995.

CHOMSKY, N. Minimalist inquiries: the framework. In: Roger Martin, David Michaels, and Juan Uriagereka (eds.). Step by Step: Essays on Minimalist Syntax in Honor of Howard Lasnik, pp. 89-155. Cambridge, MA: MIT Press, 2000.

CHOMSKY, N. Derivation by phase. In: Michael Kenstowicz (ed.). Ken Hale: A Life in Language, pp. 1-52. Cambridge, MA: MIT Press, 2001. 
CHOMSKY, N. On Phases. In: FREIDIN, R.; OTERO, C. P.; ZUBIZARRETA, M. L. (Eds.). Foundational Issues in Linguistic Theory: Essays in Honor of Jean-Roger Vergnaud. pp. 133-166. Cambridge, MA: MIT Press, 2008.

CHOMSKY, N.; LASNIK, H. The theory of principles and parameters. In: JACOBS, J. et al. (eds.). Syntax: An international Handbook of Contemporary Research. Berlin: de Gruyter, 1993.

DIKKEN, M. Den. Particles: On the Syntax of Verb-Particle, Triadic and Causative Constructions. Oxford: OUP, 1995.

DIKKEN, M. Den. When particles won't part. Ms., CUNY Graduate Center, 2003.

DIKKEN, M. Den. Relators and Linkers: the Syntax of Predication, Predicate Inversion, and Copulas. Cambridge, Mass.: The MIT Press, 2006.

DIKKEN, M. Den. Phase Extension: Contours of a theory of the role of head movement in phrasal extraction. Theoretical Linguistics 33, pp. 1-41, 2007a.

DIKKEN, M. Den. Phase Extension: A reply. Reaction to commentaries on 'Phase Extension: Contours of a theory of the role of head movement in phrasal extraction'. Theoretical Linguistics 33, pp. 133-163, 2007b.

FOLli, R.; GILliAN, R. Prepositions and Results in Italian and English: An Analysis from Event Decomposition. In: Henk Verkuyl, Henriette De Swart \& Angeliek Van Hout (eds.), Perspectives on aspect, pp. 81-105. Dordrecht: Springer, 2005.

FOLTRAN, M. J. G. D. As construções de predicação secundária no português do Brasil: aspectos sintáticos e semânticos. Tese de Doutorado - Universidade de São Paulo, 1999.

FONSECA DE OLIVEIRA, M.C.; MARCELINO. M. A construção resultativa verdadeira em português brasileiro. In: Confluência, Revista do Instituto de Língua Portuguesa. No. 47, 2. ${ }^{\circ}$ semestre de 2014, Rio de Janeiro, pp. 120-138. 2014.

FRANK, R.;VIJAY-SHANKER, K. Primitive C-Command. Syntax, 4. pp. 164-204. 2001.

GEUDER, W. Oriented adverbs: Issues in the lexical semantics of event adverbs. Doctoral Dissertation, Universität Tübingen, 2000.

GUIMARÃES, M. How Much Formal(ized) Should Generative (Transformational) Grammar Be?. Trabalho apresentado no VIII Workshop on Formal Linguistics, Universidade de São Paulo, August 6th \& 7th, 2010.

HALE, K.; KEYSER, S. J. On Argument structure and the lexical expression of syntactic relations. MIT, 1993.

HOEKSTRA, T. Small clause results. Lingua 74, pp. 101-139, 1988.

HOEKSTRA, T. Small Clauses Everywhere. Ms., University of Leiden, 1991.

HOEKSTRA, T. Aspect and theta-theory. In: ROCA, I. M. (ed.). Thematic structure: Its role in grammar. Dordrecht: Foris, 1992.

HOEKSTRA, T. Small clauses everywhere. In: Arguments and Structure: Studies on the Architecture of the Sentence. Sybesma, R.; Barbiers, S.; Dikken, M. Den; Doetjes, J.; Postma, G.; Wyngaerd, G.Vanden. (eds). Berlin: Mouton de Gruyter, 2004. 
HORNSTEIN, N. Logical Form: From GB to Minimalism. Oxford: Blackwell, 1995.

HORNSTEIN, N. Movement and control. Linguistic Inquiry 30(1): p. 69-96, 1999.

HORNSTEIN, N. Move! A Minimalist Theory of Construal. Oxford: Blackwell, 2001.

HORNSTEIN, N.; POLINSKI, M. Movement Theory of Control. Amsterdam: John Benjamins, 2010.

KAYNE, R. Connectedness and binary branching. Dordrecht: Foris, 1984.

KAYNE, R. Principles of particle constructions. In: Jacqueline Guéron and Hans-Georg Obenauer, (eds.). Grammatical Representation, pp. 101-140. Dordrecht: Foris, 1985.

KAYNE, R.S. The Antisymmetry of Syntax. Cambridge: MIT Press, 1994.

KNÖPFLE, A. Resultativas adjetivais e o estatuto nu do adjetivo. In: Revista de Estudos da Linguagem, Belo Horizonte, v. 19, n. 1, pp. 115-142, 2011.

KNÖPFLE, A. Resultativas em linguas ocidentais germânicas: generalizações descritivas, descobertas empíricas e questões analíticas. 2014. $246 \mathrm{f}$. Tese de doutorado. Universidade Federal do Paraná, Curitiba, 2014.

KNÖPFLE, A. Predicação secundária, modificação e ambiguidade: uma reflexão de base empírica. In: Revista do GELNE, Natal/RN, Vol. 19 - Número 2: pp. 101-113. Jul-Dez. 2017a.

KNÖPFLE, A. Sobre resultativas e pseudoresultativas: distinções de base empírica. DELTA: Documentação de Estudos em Lingüística Teórica e Aplicada, Ago 2017, vol.33, no.2, pp. 315-346. $2017 \mathrm{~b}$.

KRATZER, A. Building resultatives. In: MAIENBAUM, C.; WÖLLSTEIN-LEISEN, A. (eds.). Event arguments in syntax, semantics, and discourse. Tübingen: Niemeyer, 2005.

LEVIN, B.; RAPPAPORT HOVAV, M. Unaccusativity: at the syntax-lexical semantics interface. Linguistic Inquiry Monograph 26. Cambridge, Mass.: The MIT Press, 1995.

LEVINSON, L. The roots of verbs. Doctoral Dissertation, New York University, 2007.

LEVINSON, L. Arguments for pseudo-resultative predicates. In: Natural Language and Linguistic Theory, Volume 28.1, 2010.

MARCELINO, M. O parâmetro de composição e a aquisição de L2. Tese de Doutorado-Universidade Estadual de Campinas, 2007.

MARCELINO, M. Resultativas em Português Brasileiro. In: Revista Veredas: Sintaxe das Línguas Brasileiras. Volume 18/1, 2014, pp. 121-137. 2014.

MARIT, J. Syntactic Heads and Word Formation. Oxford Studies in Comparative Syntax. Oxford University Press, 2002.

MAY, R. Logical form. Cambridge, MA: MIT Press, 1985.

MÜLLER, S. Complex Predicates: Verbal Complexes, Resultative Constructions, and Particle Verbs in German. Stanford: CSLI Publications, 2002.

NEELEMAN, A.; Van de KOOT, H. Bare resultatives. Journal of Comparative Germanic Linguistics 6: 1, pp. 1-52, 2002. 
PARSONS, T. Events in the semantics of English. Cambridge, MA: MIT Press, 1990.

PULLUM, G. K. Formal linguistics meets the Boojumn. Natural language \& Linguistic theory, v. 7 (1), p8. 137-143, 1989.

RECH, N. A formação de construções resultativas no português brasileiro.In: Caderno de Estudos Linguísticos, Campinas, 49(1):79-100, 2007.

RIZZI, L. Relativized Minimality. Cambridge, Mass.: The MIT Press, 1990.

ROBERTS, I. Excorporation and minimalily. Linguistic Inquiry 22, p. 209-218, 1991.

RODRIGUES, C. Impoverished Morphology and A-movement out of Case Domains. PhD dissertation, University of Maryland, 2004a.

RODRIGUES, C. Thematic Chains. DELTA. Documentação de Estudos em Linguística Teórica e Aplicada (Online), v. 20, pp. 122-147, 2004 b.

RODRIGUES, C. Possessor Raising through Thematic Positions. In: Horsnteins, N.; Polinsky, M.. (Org.). Control as Movement. pp. 119-146. John Bejamins: Amsterdam, 2010.

ROTHSTEIN, S. Structuring events: A study in the semantics of lexical aspect. Blackwell, Oxford, 2004.

SNYDER, W. On the Nature of Syntactic Variation: Evidence from Complex Predicates and Complex Word-Formation. Language 77, 324-342, 2001.

SNYDER, W. Language Acquisition and Language Variation. The Role of Morphology. Tese (Doutorado) - MIT, 1995.

STOWELL, T. Origins of phrase structure. Unpublished doctoral dissertation - MIT, 1981.

SYBESMA, R. The Mandarin VP. Dordrecht: Kluwer Academic Publishers, 1999.

VENDLER, Z. Linguistics in philosophy. Ithaca, NY: Cornell University Press, 1967. 